\title{
Observations of precipitable water vapour over complex topography of Ethiopia from ground-based GPS, FTIR, radiosonde and ERA-Interim reanalysis
}

\author{
G. Mengistu Tsidu ${ }^{1,2,3}$, T. Blumenstock ${ }^{2}$, and F. Hase ${ }^{2}$ \\ ${ }^{1}$ Department of Physics, Addis Ababa University, P.O. Box 1176, Addis Ababa, Ethiopia \\ ${ }^{2}$ Karlsruhe Institute of Technology (KIT), Institute for Meteorology and Climate Research (IMK-ASF), Karlsruhe, Germany \\ ${ }^{3}$ Department of Earth and Environmental Sciences, Botswana International University of Science and Technology (BIUST), \\ Private Mail Bag 16, Palapye, Botswana
}

Correspondence to: G. Mengistu Tsidu (gizaw_mengistu@gmx.net)

Received: 29 April 2014 - Published in Atmos. Meas. Tech. Discuss.: 23 September 2014

Revised: 1 July 2015 - Accepted: 27 July 2015 - Published: 13 August 2015

\begin{abstract}
Water vapour is one of the most important greenhouse gases. Long-term changes in the amount of water vapour in the atmosphere need to be monitored not only for its direct role as a greenhouse gas but also because of its role in amplifying other feedbacks such as clouds and albedo. In recent decades, monitoring of water vapour on a regular and continuous basis has become possible as a result of the steady increase in the number of deployed global positioning satellite (GPS) ground-based receivers. However, the Horn of Africa remained a data-void region in this regard until recently, when some GPS ground-receiver stations were deployed to monitor tectonic movements in the Great Rift Valley. This study seizes this opportunity and the installation of a Fourier transform infrared spectrometer (FTIR) at Addis Ababa to assess the quality and comparability of precipitable water vapour (PWV) from GPS, FTIR, radiosonde and interim ECMWF Re-Analysis (ERA-Interim) over Ethiopia. The PWV from the three instruments and the reanalysis show good correlation, with correlation coefficients in the range from 0.83 to 0.92 . On average, GPS shows the highest PWV followed by FTIR and radiosonde observations. ERAInterim is higher than all measurements with a bias of $4.6 \mathrm{~mm}$ compared to GPS. The intercomparison between GPS and ERA-Interim was extended to seven other GPS stations in the country. Only four out of eight GPS stations included simultaneous surface pressure observations. Uncertainty in the model surface pressure of $1 \mathrm{hPa}$ can cause up to $0.35 \mathrm{~mm}$ error in GPS PWV. The gain obtained from using observed sur-
\end{abstract}

face pressure in terms of reducing bias and strengthening correlation is significant but shows some variations among the GPS sites. The comparison between GPS and ERA-Interim PWV over the seven other GPS stations shows differences in the magnitude and sign of bias of ERA-Interim with respect to GPS PWV from station to station. This feature is also prevalent in diurnal and seasonal variabilities. The spatial variation in the relationship between the two data sets is partly linked to variation in the skill of the European Centre for Medium-Range Weather Forecasts (ECMWF) model over different regions and seasons. This weakness in the model is related to poor observational constraints from this part of the globe and sensitivity of its convection scheme to orography and land surface features. This is consistent with observed wet bias over some highland stations and dry bias over few lowland stations. The skill of ECMWF in reproducing realistic PWV varies with time of the day and season, showing large positive bias during warm and wet summer at most of the GPS sites.

\section{Introduction}

Water vapour is one of the most important greenhouse gases. Its radiative characteristics play a great role in determining the magnitude of the greenhouse effect and the planetary albedo. These, together with its unique thermodynamic properties, dictate the hydrological cycle and energy budget of the 
Earth's atmosphere. For instance, water vapour acts to amplify other feedbacks (e.g. cloud and albedo feedbacks). An increase of temperature can result in an increase in total precipitable water vapour (PWV) since the equilibrium vapour pressure increases with increasing temperature (Stevens and Bony, 2013, and references therein). Therefore, on longer timescales, water vapour changes are thought to contribute to an important positive feedback mechanism for climate change. Warming of the surface, particularly the sea surface, leads to enhanced evaporation. Enhanced water vapour in the lower troposphere results in further warming, allowing a higher water vapour concentration, thereby creating a positive feedback. Mears et al. (2007) have determined that an increase of the temperature of $1 \mathrm{~K}$ will result in a 5-7\% rise in PWV. Thus, long-term changes in the amount of water vapour in the atmosphere need to be monitored as part of an effort to understand and predict its complex and amplifying role in climate change.

Atmospheric water vapour exhibits substantial diurnal variations (e.g. Dai and Hove, 2002; Wang et al., 2007, and references therein). These variations affect surface and atmospheric long-wave radiation and atmospheric absorption of solar radiation as well as other processes, such as diurnal variations in moist convection and precipitation, surface wind convergence and surface evapotranspiration. Unfortunately, there is a lack of data with high temporal resolution to investigate most of the above processes and their linkage to water vapour in greater detail.

One way to monitor water vapour is through measurements of precipitable water (PWV) using a variety of instruments onboard different platforms (e.g. Ning et al., 2015, and references therein). PWV measurements can also be used to understand weather and improve forecasting as it is a crucial element in the development of clouds and precipitation. In the past, weather service centres relied on information from radiosondes and satellites to complement analysis from models. However, the density of radiosonde observations is very sparse and nonuniform often related to running costs. As a result, it is rare to find more than one site per country over many parts of the globe and the situation in Africa is even worse. Moreover, sustainability of the radiosonde sites has been a challenge, which is reflected in data gaps in historical time series. Satellite observations are less likely to suffer from similar problems; however, the PWV estimate from satellites is also complicated over land due to surface temperature and albedo variability.

In view of these limitations, there have been efforts to develop new observing systems (e.g. global positioning system, GPS). The use of GPS has been extended to investigation of the upper and lower atmosphere from its traditional application of position determination in recent decades. GPS can provide a high-resolution continuous measurement of zenith tropospheric delay from which a near real-time total precipitable water vapour around a ground GPS-receiver site can be derived. Moreover, apart from continuity and high tem- poral resolution, a GPS receiver can run automatically once installed. As a result, considerable effort has been devoted to deriving PWV using ground-based GPS measurements (e.g. Bevis et al., 1992, 1994; Rocken et al., 1993, 1997; Bollmeyer et al., 2015) at high temporal resolutions, validating radiosonde, satellite and reanalysis data (e.g. Yang et al., 1999; Guerova et al., 2003; Dietrich et al., 2004; Van Baelen et al., 2005; Bock et al., 2010; Schneider et al., 2010; Buehler et al., 2012), improving numerical weather prediction (e.g. Vedel and Huang, 2004; Vedel et al., 2004; Gendt et al., 2004)), creating near global and high temporal PWV data sets (e.g. Gradinarsky et al., 2002; Wang et al., 2007, 2009), and studying 3-D heterogeneity of the troposphere based on tomographic methods (e.g. Braun et al., 2003; Champollion et al., 2005). Despite these considerable efforts to exploit steadily expanding multi-purpose ground-based GPS receiver networks, this capability has not been replicated over Africa due to the lack of a GPS network, with exceptions over southern Africa (e.g. Combrink et al., 2004, and references therein). Most efforts to validate satellite and model estimates of precipitable water over Africa are hindered due to lack of GPS and other ground-based atmospheric observing systems as well as large data gaps (e.g. Fetzer et al., 2003; King et al., 2003; Bock et al., 2007a).

However, a recent increase in the number of GPS ground receiver sites for geodetic studies over northern Africa and the African Monsoon Multidisciplinary Analyses (AMMA) project over west Africa has initiated investigation of PWV over these regions (Bock et al., 2007a; Koulali et al., 2011). For instance, Koulali et al. (2011) have used GPS PWV and other complementary observations to show that the monthly mean PWV variation over Morocco is controlled by the upper layer zonal and meridional moisture flux. Bock et al. (2007a) have used some scattered GPS receiver stations over Africa and compared them to independent observations, and to 40-year ECMWF Re-Analysis (ERA-40) and National Centers for Environmental Prediction reanalysis 2 (NCEP2) model simulations. While these studies hardly represent the whole of Africa, they have made important contributions to filling the existing data gaps and to understanding of water vapour variability. However, there is no similar work over the East African Rift Valley region, a region with almost no observations until recently. A number of GPS sites have been installed since 2007 to monitor geodetic activity either in campaign mode or as permanent stations along the Great Rift Valley region and adjoining Ethiopian highlands. Most of these stations are still operating and providing data despite interruptions at some stations. Therefore, the use of the data from these stations for investigating PWV variability over the region and validating reanalysis data is of considerable interest.

ERA-Interim is a global reanalysis data set that provides PWV. Moreover, ERA-Interim PWV has been found to capture the truth elsewhere in the continent from previous studies (e.g. Bock et al., 2005, 2007a; Koulali et al., 2011) which 

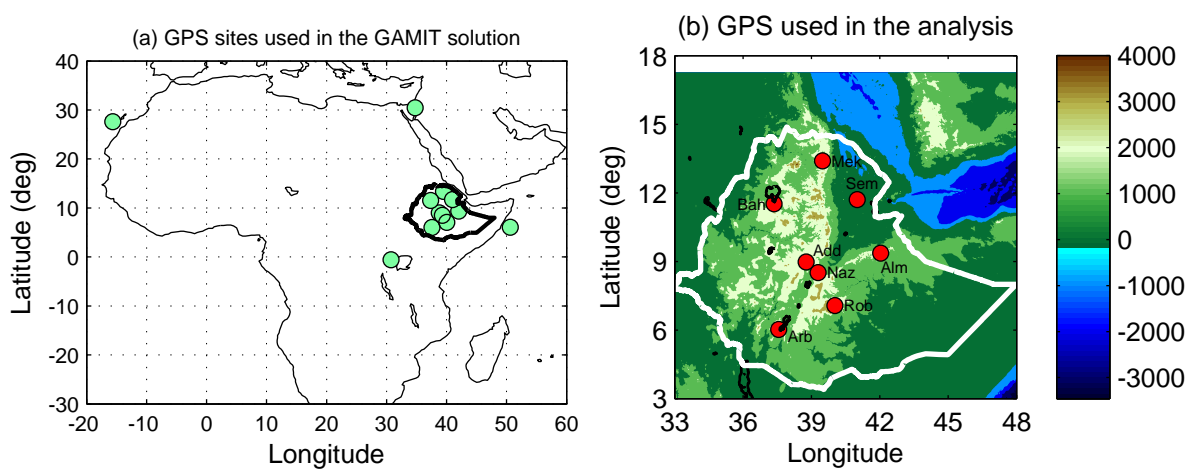

Figure 1. UNAVCO GPS ground receiver sites used in GPS solution using GAMIT software over the region (a) and locations of GPS receivers used in the analysis of PWV, nearby lakes and topography of the country (altitude in metres) (b). The green circles show sites of GPS stations used in the GAMIT network solution. The red circles represent eight GPS sites considered in the analysis. Lakes are shown by the black contour lines. The smaller lakes appear in the map as dots due to the scale. The full names of the stations corresponding to short names in the map are given in Table 3 .

is less complex in terms of topography as compared to eastern Africa. This encouraged us to use ERA-Interim PWV in this study to assess how good it is over Ethiopia with respect to coincident measurements from GPS, Fourier transform infrared spectrometer (FTIR) and radiosondes. In contrast to the radiosonde data, the ground-based GPS data have not yet been assimilated in the reanalysis output. In this respect, GPS PWV can serve as an independent validation data set suitable for the evaluation of reanalysis (e.g. Bock et al., 2007a, and references therein) and climate models (Ning et al., 2013).

For the reasons outlined above, a formal quality assessment of observed PWV in Addis Ababa is performed. The spatial and temporal variabilities of PWV in Ethiopia as captured by GPS and ERA-Interim and the consistency between the two data sets are also investigated.

The paper is structured as follows. In Sect. 2, the data and the methodology used in this work are presented. Results and discussion are given in Sect. 3, and finally conclusions are given in Sect. 4.

\section{Data and methodology}

The observations of atmospheric precipitable water vapour over Addis Ababa are performed using ground-based GPS receivers, FTIR, and radiosondes. Radiosonde observations have been carried out daily at the Addis Ababa synoptic meteorological station since 1969 despite gaps due to measurement interruption and problems with data quality. The FTIR was installed in May 2009 and monitors most atmospheric trace gases by recording solar absorption spectra. Groundbased GPS receivers are installed not only in Addis but also along the Ethiopian Rift Valley and neighbouring highlands as part of monitoring tectonic movement at different times over the last few years (see filled circles in Fig. 1). Correlation coefficients, bias and root mean square deviation (RMSD) are used to assess the level of agreement between the different data sets. The bias is calculated as the mean of the differences in this work. In the following, the respective data sets and methodologies used in acquiring them from these instruments are described.

\subsection{FTIR observations}

The Addis Ababa FTIR site is a tropical high-altitude site at $9.01^{\circ} \mathrm{N}$ latitude, $38.76^{\circ} \mathrm{E}$ longitude, $2443 \mathrm{~m}$ altitude above sea level. The FTIR instrument is a commercial Bruker IFS-120M spectrometer. Two detectors, mercury-cadmiumtelluride ( $\mathrm{HgCdTe})$ and indium-antimonide (InSb) detectors, allow wide spectral coverage and enable retrieval of several trace species (Takele Kenea et al., 2013) from the spectra recorded at a spectral resolution of $0.005 \mathrm{~cm}^{-1}$.

The retrieval method is a sequential procedure in which solar lines are first retrieved, and then used in the subsequent retrieval of water vapour. These results are both used in the following retrievals of $\mathrm{N}_{2} \mathrm{O}, \mathrm{CH}_{4}, \mathrm{O}_{3}$ and other gases. Daily pressure and temperature vertical profiles used in the forward radiative transfer model during the retrieval of trace gases from the FTIR spectra were taken from the automailer system of Goddard Space Flight Center. The climatological profiles were based on data from NCEP. The retrieved state vector contains the retrieved volume mixing ratios of the target gas defined at 44 levels in the atmosphere from the surface up to $120 \mathrm{~km}$, as well as the retrieved interfering species column amounts, and some model parameters. The model parameters include the baseline slope and instrumental line shape (Hase et al., 1999). The retrieval of $\mathrm{H}_{2} \mathrm{O}$ volume mixing ratio (VMR) is performed on a logarithmic scale because of the large vertical dynamic range and high variability near the boundary layer. The PWV can be determined by integrating VMR over the whole altitude range or directly from the column amount of water vapour. In this study, the latter was followed to avoid error due to numerical integration. 


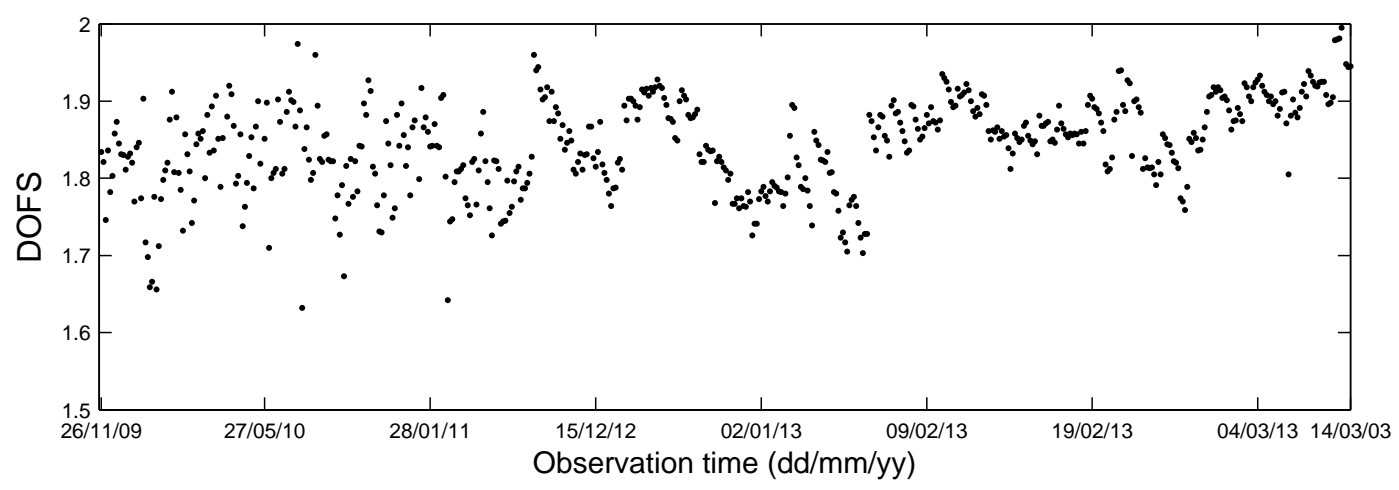

Figure 2. Degrees of freedom for signal for all FTIR measurements at Addis Ababa.

Table 1. The spectral microwindows used for retrieval of water vapour and the major interfering species considered.

\begin{tabular}{ll}
\hline Microwindow $\left(\mathrm{cm}^{-1}\right)$ & Interfering species \\
\hline $2659.0-2661.0$ & \\
$2662.0-2664.2$ & \\
$2665.8-2666.8$ & \\
$2677.2-2678.2$ & $\mathrm{HDO}, \mathrm{O}_{3}, \mathrm{CH}_{4}, \mathrm{HCl}, \mathrm{C}_{2} \mathrm{H}_{6}$ \\
$2974.2-2975.6$ & \\
$2983.1-2985.2$ & \\
$2991.0-2996.0$ & \\
\hline
\end{tabular}

The retrieval of vertical profile of trace gases from groundbased FTIR spectra depends on the sensitivity of the absorption lines to pressure broadening such that the spectral line centres provide information about the higher altitudes of the distribution while the wings of a line give information about the lower altitudes. This entails that the information content of the retrieval will strongly depend on the choice of the absorption lines and use of accurate pressure and temperature profiles (Mengistu Tsidu, 1998; Echle et al., 2000, and references therein). The spectral microwindows used for the water vapour retrieval include seven spectral ranges in the midinfrared shown in Table 1. Table 1 also shows the interfering species jointly retrieved with water vapour. The spectral microwindows are subset of the microwindows used by Schneider et al. (2012) and selected based on their strong sensitivity to pressure broadening. However, the contribution of pressure and temperature uncertainty to the overall error budget in retrieval of trace gases from FTIR absorption spectra is insignificant (Mengistu Tsidu, 1998).

The retrieved water vapour profiles are characterized in terms of information content based on degrees of freedom for signal (DOFS), vertical resolution, and different error sources following the optimal estimation method (Rodgers, 1976, 2000). The trace of the averaging kernel matrix, the DOFS, represents the number of independent pieces of information retrieved from the measurements. It varies between
1.6 and 2.0 (Fig. 2) suggesting the existence of about two independent layers. This is consistent with the values found by others (e.g. Schneider et al., 2006) although further marginal improvement can be achieved with an increase in the number of co-added scans during FTIR measurements.

The retrieval algorithm allows the characterization of the error sources, such as temperature, noise, instrumental line shape, solar lines, line of sight, baseline, and spectroscopy. However, what is interesting in the context of this study is to investigate how the total error due to uncertainties in these parameters affects the PWV. The systematic and statistical errors in PWV were obtained through optimal estimation procedure. Figure 3 shows (a) precipitable water vapour and (b) statistical error, and (c) systematic error in PWV for all measurements. The statistical error in PWV is small and lower than $0.1 \mathrm{~mm}$ throughout most of the measurements. The systematic error varies between 0.2 and $0.6 \mathrm{~mm}$ for most of the observations, exceeding $0.6 \mathrm{~mm}$ in a few cases.

\subsection{GPS observations}

The zenith tropospheric delay can be estimated from measurements of the delay to each GPS satellite in view of a ground station. Signals from several GPS satellites, up to 11, can be received at any given time over a given GPS ground receiver site. However, a network of ground GPS receivers is required to determine GPS orbits and biases due to satellite clocks, receiver clocks, and receiver biases. The analysis of GPS data obtained by such a network produces an estimate of total tropospheric zenith delay (TZD) which can be split into dry hydrostatic (ZHD) and wet zenith (ZWD) delays. The ZWD is that part of the range delay that can be attributed to the water vapour in the troposphere. ZWD can be determined from TZD GPS measurement and ZHD corrected a priori using the Saastamoinen (1972) formula.

If the vertically integrated water vapour overlying a receiver is stated in terms of PWV, then this quantity can be related to the $\mathrm{ZWD}$ at the receiver by

$\mathrm{PWV}=\Pi \times \mathrm{ZWD}$, 
(a) PWV
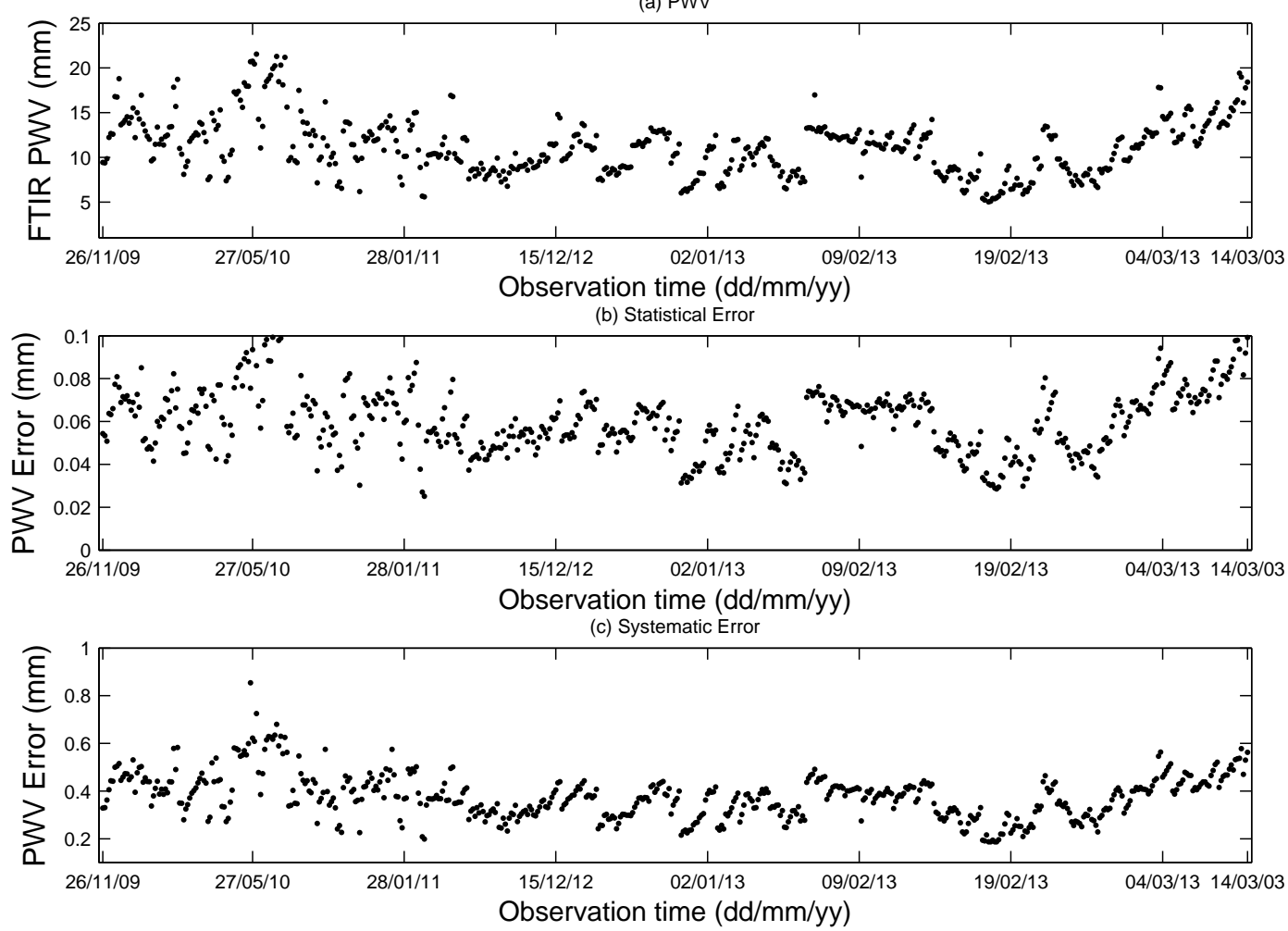

Figure 3. FTIR observations: (a) PWV; (b) statistical error due to random retrieval errors in PWV; and (c) systematic error in PWV.

where the ZWD is given in units of length, and the dimensionless constant of proportionality $\Pi$ is a function of $T_{\mathrm{m}}$ given by an empirical model

$\Pi=\frac{10^{6}}{\rho R_{\mathrm{v}}\left[\left(\frac{k_{3}}{T_{\mathrm{m}}}\right)+k_{2}^{\prime}\right]}$,

where $\rho$ is the density of liquid water at the surface, $R_{\mathrm{V}}$ is the specific gas constant for water vapour, $k_{2}^{\prime}=22.1 \pm$ $2.2 \mathrm{~K} \mathrm{mb}^{-1}$ and $k_{3}=(3.739 \pm 0.012) \times 10^{5} \mathrm{~K}^{2} \mathrm{mb}^{-1}$ are constants (Bevis et al., 1994). $T_{\mathrm{m}}$ is a weighted mean temperature of the atmosphere and is usually given in terms of surface temperature. We used $T_{\mathrm{m}}$ estimates computed from ECMWF temperature and humidity profiles and made available at the Technical University of Vienna (http://ggosatm. hg.tuwien.ac.at/DELAY/).

The GPS data are processed with the GPS analysis package at MIT (GAMIT) software v10.32 (King and Bock, 2006), which solves for the tropospheric and other parameters using a constrained least squares algorithm. The input data required by GAMIT are the raw GPS observations, Earth orientation parameters, and $2 \mathrm{~h}$ orbit predictions from the hourly GPS satellite orbit product generated by the Scripps Orbit and Permanent Array Center (SOPAC). The software is based on a method referred to as a network solution in which data from several sites are processed together. The Global Mapping Function (Boehm et al., 2007) was used for mapping ZHD and ZWD into the slant path directions of the GPS satellites at each epoch. The Vienna Mapping Function based on exact ray traces through the refractivity profiles derived from ECMWF was used. The elevation cut-off angle was fixed to $10^{\circ}$. This translates to a radius of about $28 \mathrm{~km}$ at an altitude of $5 \mathrm{~km}$ (note that most water vapour is found within the first $5 \mathrm{~km}$ layer). This implies that GPS ZWD is close to that of a purely vertical integral measurement, and hence it can represent PWV at the ground-based GPS receiver location. The GPS data were processed in doubledifference mode in $24 \mathrm{~h}$ observing sessions within the University NAVstar COnsortium (UNAVCO) network in the region shown in Fig. 1a.

The PWV was determined from GPS ground receivers installed along and across the Great Rift Valley. GPS stations installed along the main rift system over Ethiopia are Semera in the north, Nazerate in the centre and Arba Minch in the south, while those installed across the rift systems include Robe in the southern highlands, Addis Ababa in the central highlands, Alemaya in the southeastern highlands, Mek'ele in the northern highlands and Bahir Dar in the northwestern highlands of the country as indicated in Fig. 1b. The PWV is derived for 2007-2011 with some data gaps at all stations but at different times as indicated in Table 2. The eight GPS stations represent different climate regimes in the country (Mengistu Tsidu, 2012). 
Table 2. The observation periods covered in the study (see also Fig. 4 for data gaps during the period).

\begin{tabular}{lcccc}
\hline Station & FTIR & GPS & Radiosonde & ERA-Interim \\
\hline Addis Ababa & $2009-2011$ & $2007-2011$ & $2007-2011$ & $2007-2011$ \\
Mek'ele & & 2008 & & $2007-2011$ \\
Robe & $2007-2009$ & & $2007-2011$ \\
Alemaya & & $2007-2009$ & & $2007-2011$ \\
Arba Minch & $2007-2011$ & & $2007-2011$ \\
Bahir Dar & $2007-2011$ & & $2007-2011$ \\
Semera & & $2007-2009$ & & $2007-2011$ \\
Nazerate & $2007-2011$ & $2007-2011$ \\
\hline
\end{tabular}

In the absence of in situ meteorological data, the best choice of pressure and temperature for a site comes from the global pressure and temperature (GPT) model (Boehm et al., 2007). Since we have surface observations at only four of the eight GPS stations (see Table 3), we used GPT as well as observed pressure and temperature. The difference between PWV estimates based on pressure and temperature from the GPT model and observations is used to assess the performance of the GPT model and the error that can be caused by using it in places where observations are not available in the country.

The quality of GPS PWV can be assessed from the PWV estimation error. The estimation error is obtained from the residual of constrained least squares solution as described by Ge et al. (2002) and Jin and Park (2005) and references therein. Figure 4 shows PWV estimation error for all sites. Inspection of the estimation error shows an increase in scatter at 00:00 UTC for all eight GPS sites. This has also been reported by Bock et al. (2008). The estimation error for Addis Ababa (Fig. 4a) remains lower than $2 \mathrm{~mm}$ most of the time. However, there are also higher values which are filtered out for future analysis. A similar error pattern is also observed for Bahir Dar (Fig. 4f). The estimation error at most of the remaining GPS sites (Fig. $4 \mathrm{~b}-\mathrm{e}, \mathrm{g}-\mathrm{h}$ ) is on the order of $1.2 \mathrm{~mm}$ on average with varying data gaps.

The error propagation from uncertainty in zenith path delay, surface pressure and atmospheric mean temperature to PWV from the theoretical and empirical relationships used in the linear least squares solutions has also been estimated assuming uncertainty of $4 \mathrm{~mm}$ in zenith path delay, $1.65 \mathrm{hPa}$ in surface pressure and $1.3 \mathrm{~K}$ in mean atmospheric temperature as described by Wang et al. (2007) for the Addis Ababa GPS site. These uncertainties contribute an error of about $1.32 \mathrm{~mm}$, in agreement with the finding of Wang et al. (2007). The surface pressure uncertainty alone contributes about $0.35 \mathrm{~mm} \mathrm{hPa}^{-1}$. However, the uncertainty in surface pressure could be much higher when the surface pressure from the GPT or reanalysis such as ECMWF is used in the estimation of PWV. For instance, the surface pressure difference between the GPT model and the measurements within a radius of $50 \mathrm{~km}$ from four of the GPS stations is found to span a range of $1-10 \mathrm{hPa}$, suggesting that the GPT model
Table 3. The ground-based GPS receivers used in this study and their geocoordinates.

\begin{tabular}{lcrrr}
\hline Station & Abbrev. & Long. $\left(^{\circ}\right)$ & Lat. $\left({ }^{\circ}\right)$ & Alt. $(\mathrm{m})$ \\
\hline Addis Ababa $^{1}$ & Add & 38.76 & 9.03 & 2438.94 \\
Mek'ele $^{1}$ & Mek & 39.48 & 13.39 & 2226.04 \\
Robe & Rob & 40.03 & 7.07 & 2458.19 \\
Alemaya & Ale & 42.03 & 9.36 & 2042.31 \\
Arba Minch & Arb & 37.56 & 6.02 & 1199.86 \\
Bahir Dar $^{1}$ & $\mathrm{Bah}$ & 37.36 & 11.52 & 1793.12 \\
Semera $^{1}$ & $\mathrm{Sem}$ & 41.01 & 11.70 & 418.31 \\
Nazerate $^{1}$ & $\mathrm{Naz}$ & 39.29 & 8.51 & 1722.60 \\
\hline
\end{tabular}

${ }^{1}$ GPS stations for which surface observations are available.

works well at some stations and poorly at others. This difference must come from the different orography and could potentially be mitigated via a high-resolution digital elevation model. The impact of possible inaccuracy of the GPT model data used in retrieving GPS PWV is investigated at Addis Ababa, Bahir Dar, Mek'ele and Nazerate sites using surface pressure measurements from nearby synoptic stations. The surface pressure measurements were first adjusted to the altitude of GPS stations by vertically interpolating them following procedure proposed by Wang et al. (2007) before using them in GPS PWV estimation. Only surface pressure measurements with good-quality flags were used for this purpose. This and the large gaps in the surface pressure measurements dramatically reduced the number of GPS PWV observations that were subsequently used in the comparison with other instruments and reanalysis in contrast to the situation when the GPT model was used. However, apart from this decrease in the number coincident observations, the bias in the GPS PWV has been reduced significantly upon using observed surface pressure as discussed in Sects. 3.1-3.2.

\subsection{Radiosonde soundings}

The radiosonde sounding data at Addis Ababa are taken from the Integrated Global Radiosonde Archive (IGRA) at the National Climatic Data Center (NCDC). The IGRA archive contains quality-assured data (Durre et al., 2006). However, IGRA does not include radiative bias correction or filled data gaps; in effect, the archive contains sounding data with a lot of missing values. Moreover, the altitude coverage of most measurements is not sufficient to compute PWV. As a result, only a relatively small number of observations with data extending to altitudes above $200 \mathrm{hPa}$ are available that are used in the following intercomparisons. Dew point temperature is computed from dew point depression and temperature sounding, which is then used to determine vapour pressure. The vapour pressure and surface pressure are used to compute specific humidity. The precipitable water vapour (PWV 

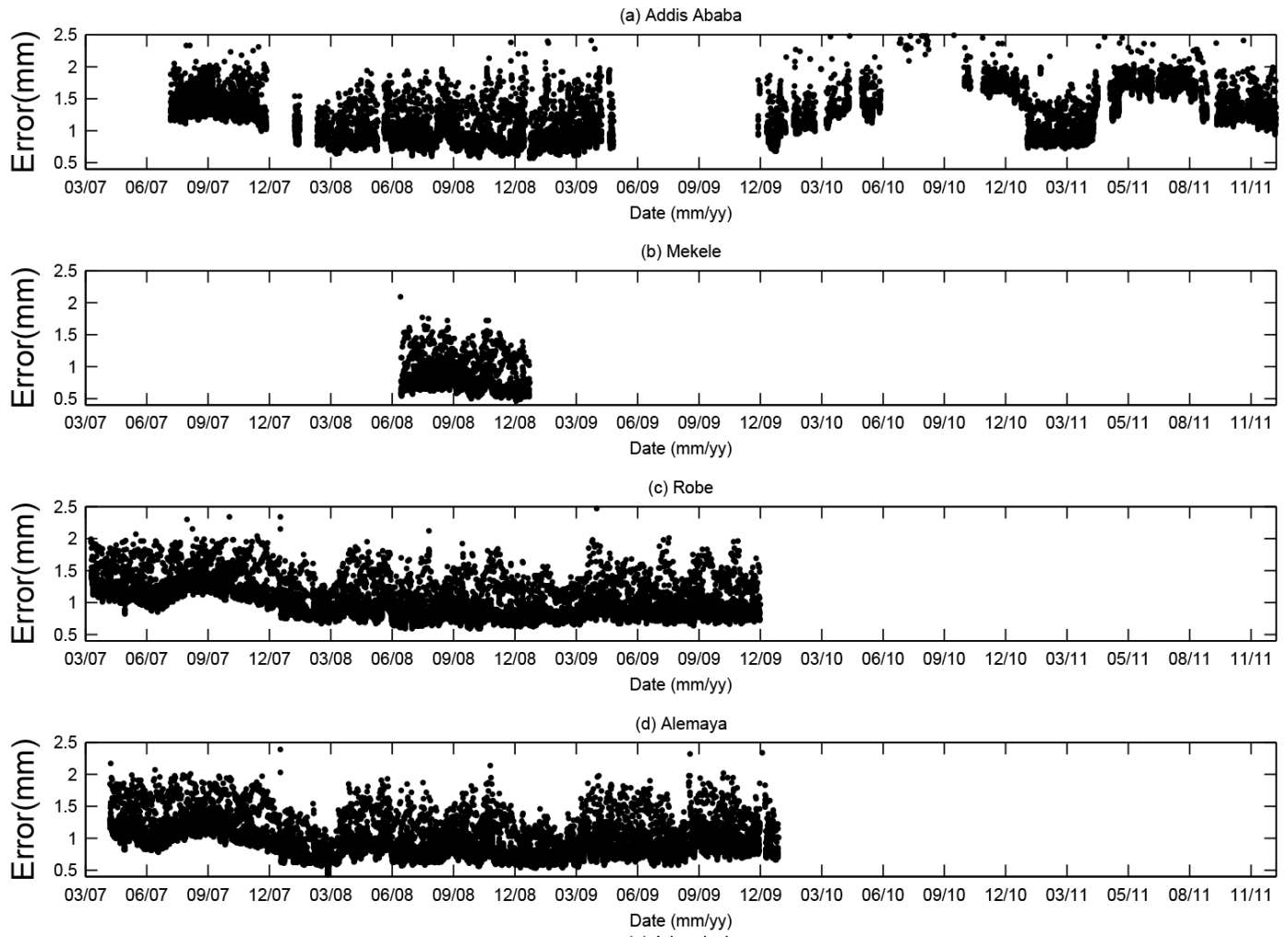

Date $(\mathrm{mm} / \mathrm{yy})$
(e) Arbaminch
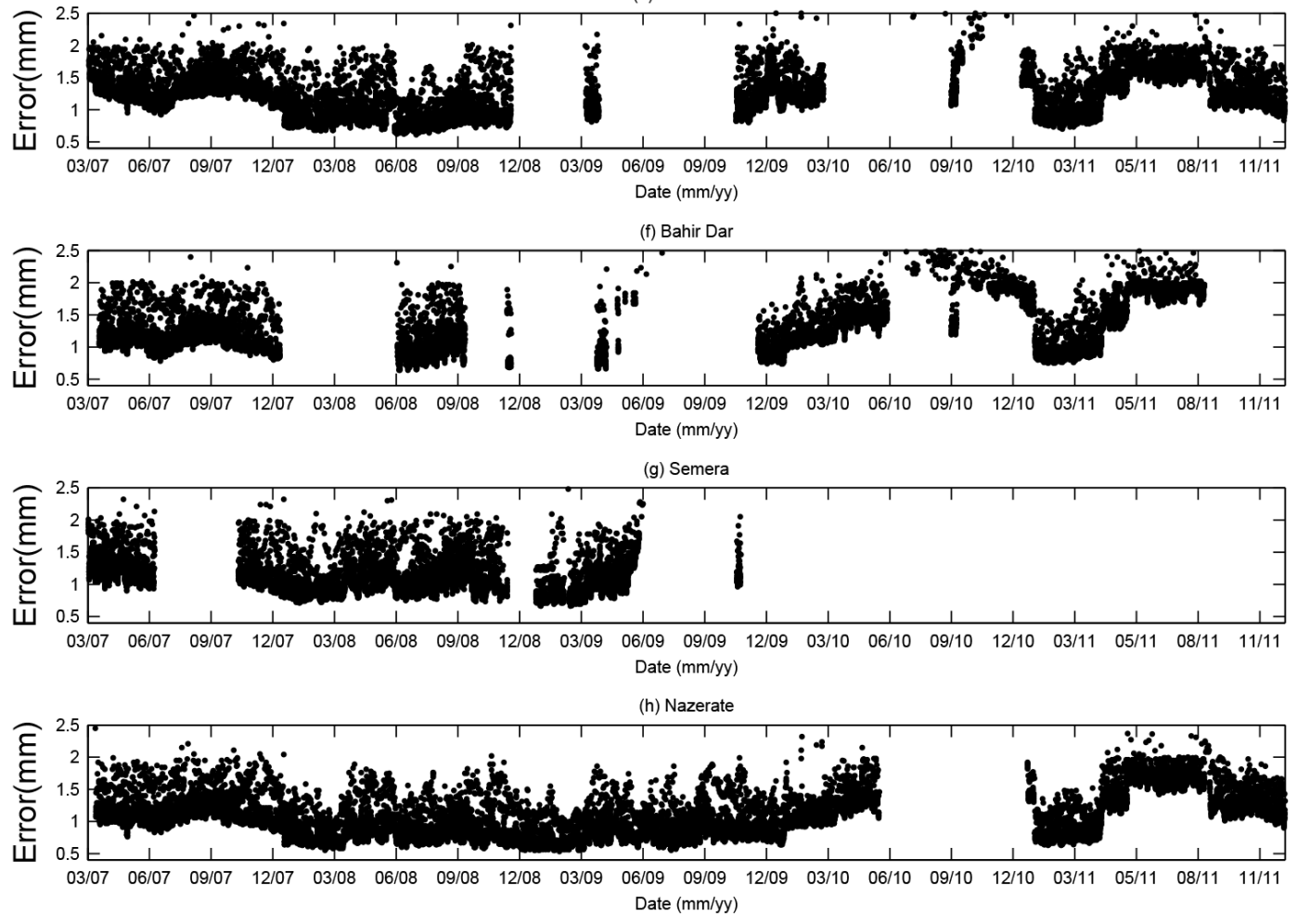

Figure 4. Formal GPS PWV error from GAMIT least squares solution for each GPS station shown on the top of each panel (a)-(h). The panels are scaled to the same time axis range for the sake of comparison. 
(a) 20070101

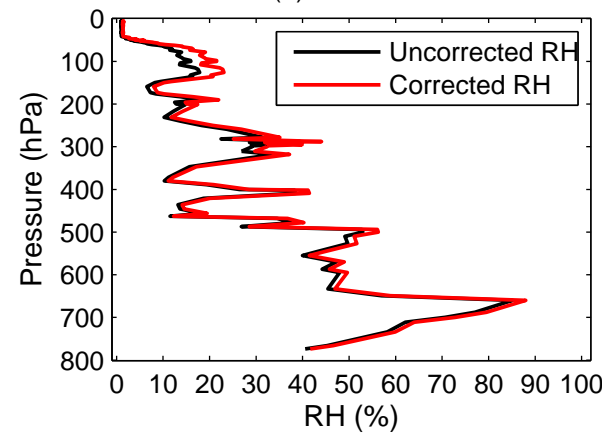

(b) Mean SRDB correction

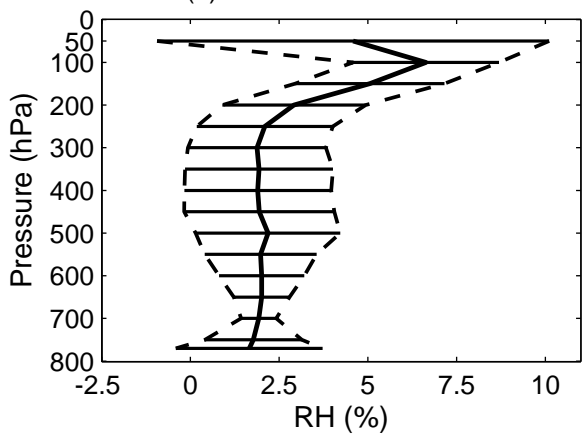

Figure 5. Estimated solar radiation dry bias in radiosonde relative humidity. (a) Typical correction in RH due to SRDB; and (b) mean relative humidity SRDB correction (solid line) and corresponding standard deviation (error bar).

in units of $\left.\mathrm{kg} \mathrm{m}^{-2}(\mathrm{~mm})\right)$ is then determined from

$\mathrm{PWV}=\frac{1}{g_{\mathrm{o}}} \int_{p_{\mathrm{o}}}^{p_{\text {surf }}} q(p) \mathrm{d} p$,

where $q(p)$, the specific humidity as a function of atmospheric pressure $p$, is given in units of $\mathrm{kg} \mathrm{kg}^{-1}$ and $g_{0}=$ $9.80665 \mathrm{~m} \mathrm{~s}^{-2}$.

The slow response of humidity sensors and radiation exposure related to temperature sensors at many stations are sources of problems. Various methods have been developed to correct known humidity observational errors for individual types of radiosondes through either statistical approaches (Turner et al., 2003; Voemel et al., 2007) or laboratory or physical correction schemes. The radiosonde data from the Addis Ababa radiosonde station have undergone quality checks by IGRA based on scrutiny for the presence of physically implausible values, internal inconsistencies among variables, climatological outliers, and temporal and vertical inconsistencies in temperature (Durre et al., 2006).

The type of radiosonde used is the Vaisala RS92, which uses a capacitive sensor and the measurement, which is carried out once per day, is taken at 12:00 UTC. The Vaisala RS92 is found to be the most accurate from comparison with the Cryogenic Frostpoint Hygrometer during the Atmospheric Infrared Sounder (AIRS) Water Vapour ExperimentGround (AWEX-G), as demonstrated by mean percentage accuracy within 5-10\% in the lower to upper troposphere (Miloshevich et al., 2006). Despite its improvement over its predecessors, the RS92 still suffers from solar radiation dry bias (SRDB) since the sensors are not equipped with the radiation/rain shielding cap installed on the RS80. Therefore, correction of the SRDB in relative humidity ( $\mathrm{RH})$ measurements is necessary. Bias correction of this kind has been reported for different radiosonde types (e.g. Agusti-Panareda et al., 2009; Miloshevich et al., 2004; Wang et al., 2013, and references therein). Since we do not have night-time measurements, we employed the method proposed by Wang et al. (2013) and used the Vaisala RS92 solar radiation temperature correction table (RSN2010, available at http://www. vaisala.com/en/products/soundingsystemsandradiosondes/ soundingdatacontinuity/RS92DataContinuity/Pages/ revisedsolarradiationcorrectiontableRSN2010.aspx) to interpolate the correction values to the pressure and elevation angle of the observation. Figure 5 shows a typical measured and corrected RH for solar radiation dry bias (panel a) and the mean $\mathrm{RH}$ correction and its scatter (panel b) from 85 soundings, taken during the study period and covered altitude range from surface to $50 \mathrm{hPa}$. The maximum RH correction of about $6 \%$ is obtained near the tropopause, while the correction in most parts of the troposphere is lower than $2.5 \%$ in agreement with previous understanding (e.g. Miloshevich et al., 2006; Wang et al., 2013). The mean SRDB RH correction implies the presence of a mean dry bias of up to $0.51 \pm 0.19 \mathrm{~mm}$ in radiosonde PWV.

\subsection{ERA-Interim data}

ECMWF is currently providing ERA-Interim reanalysis data based on cycle $31 \mathrm{r} 2$ of the Integrated Forecast System (IFS). Relative to the ERA-40 system, which was based on IFS cycle 23r4, ERA-Interim incorporates many important IFS improvements such as model resolution and physics changes, the use of four-dimensional variational data assimilation (4D-Var), and various other changes in the analysis methodology (Dee et al., 2011). The precipitable water vapour from reanalysis data sets has been found to be in good agreement with in situ and GPS observations, in particular, good agreement between ERA-40 PWV and GPS PWV at some GPS sites in western and northern Africa (Bock et al., 2007a). In particular, Bock et al. (2011) indicated the presence of relatively good agreement between GPS PWV and ERA-Interim PWV with respect to those between GPS PWV and other reanalyses (e.g. NCEP1, NCEP2) over western Africa.

For the latest ERA-Interim that is used in this work, the agreement with observations is significantly improved for 

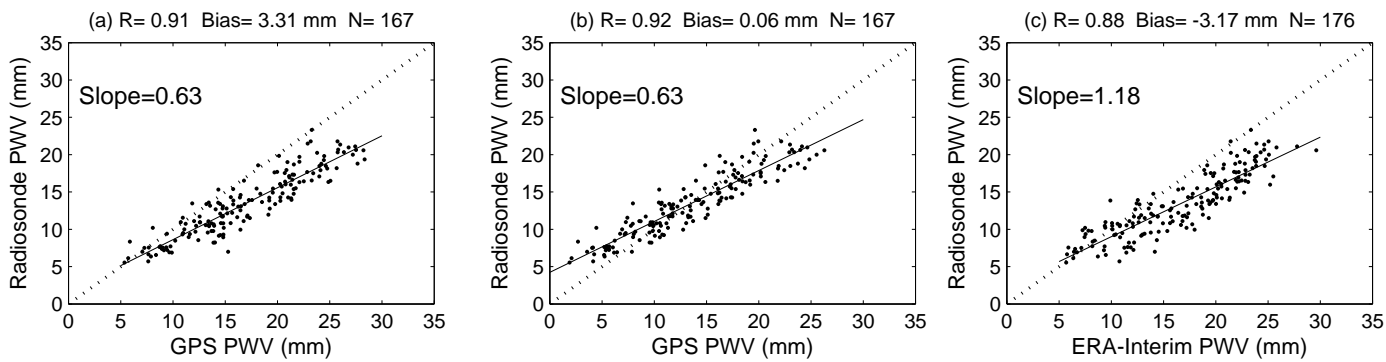

Figure 6. Comparison of GPS-derived and radiosonde PWV at 12:00 UTC for coincident measurements when (a) GPT surface pressure and (b) observed surface pressure are used in GPS PWV evaluations; (c) comparison of ERA-Interim reanalysis and radiosonde PWV at 12:00 UTC when ERA-Interim PWV is adjusted to altitude of radiosonde launch site using Eq. (4).

most variables (Berrisford et al., 2009; Dee et al., 2011). PWV has been evaluated with microwave satellite estimates over ocean only (Dee et al., 2011) and with ground-based GPS by Buehler et al. (2012). It needs to be noted that while radio occultation observations by COSMIC have been assimilated since 2006, no ground-based GPS data are incorporated in ERA-Interim. This has been noticed indirectly in the large discrepancy found in a recent comparison of ERAInterim precipitation with observations (Mengistu Tsidu, 2012). Nevertheless, in a broader global context, ERAInterim analysis provides optimal humidity estimates from high-quality observations among multi-satellite sounders, imagers, and radiosondes through a data assimilation system. The data quality is granted through consistency checks among observational data sources used in the assimilation through a series of adaptive bias correction and quality control procedures (Auligne et al., 2007).

ERA-Interim PWV has been corrected for the altitude difference between the ERA-Interim and the actual GPS site altitude using

$\Delta \mathrm{PWV}=\rho_{\nu} \Delta h\left(1-\frac{\rho_{\nu} \Delta h}{2 \mathrm{PWV}}\right)$,

where $\rho_{\nu}$ is water vapour density and $\Delta h$ is altitude difference between ERA-Interim nearest vertical grid point and the GPS site as proposed by Bock et al. (2007a). Since we have used the high-resolution version of ERA-Interim, the correction made in this manner is insignificant as will be shown later.

\section{Results and discussion}

\subsection{Intercomparison of PWV from different instruments and reanalysis over Addis Ababa}

Addis Ababa is used as a case study to demonstrate the reliability of PWV from GPS, FTIR, radiosondes and ERAInterim and their consistency with each other. The FTIR and GPS are co-located at Addis Ababa geophysical observatory at an altitude of $2438.94 \mathrm{~m}$ whereas the daily radiosonde sta- tion is only about $4 \mathrm{~km}$ away from the Addis Ababa geophysical observatory at an altitude approximately $80 \mathrm{~m}$ lower. Moreover, the radiosondes are part of the global data set assimilated in the ERA-Interim model.

Figure $6 \mathrm{a}-\mathrm{b}$ show comparison of radiosonde and GPS PWV determined based on GPT surface pressure (panel a) and observed surface pressure (panel b) at Addis Ababa at 12:00 UTC as described in Sect. 2.2. There is considerable improvement in the agreement of the two data sets as reflected in the sharp drop in the wet bias from $3.3 \mathrm{~mm}$ in GPS PWV with respect to radiosonde when GPT is used (Fig. 6a) to $0.1 \mathrm{~mm}$ after observed surface pressure is employed (Fig. 6b). Moreover, the RMSD has improved from 4.3 to $2.5 \mathrm{~mm}$. However, the correlation did not show significant improvement, suggesting that inaccuracy in the surface pressure used in the GPS PWV processing affects the magnitude, not the phase of the variation, as it is part of a systematic error. Figure $6 \mathrm{a}-\mathrm{b}$ also illustrate the dry bias by the increased difference between radiosonde and GPS PWV for high PWV values. Almost identical coincident ERAInterim PWV comparison with radiosonde exhibits the dry bias shown in Fig. 6c. Note that Fig. 6c represents ERAInterim and radiosonde after adjusting ERA-Interim PWV for altitude difference between nearest horizontal ECMWF grid point and radiosonde site. The applied correction is minor due to the proximity of the high-resolution model horizontal grid (i.e. $0.75 \times 0.75^{\circ}$ horizontal resolution) to the Addis Ababa synoptic station from where radiosondes are launched. The use of nearest horizontal grid point is recommended by ECMWF for verification with sparse observations (Bock et al., 2005). The radiosonde PWV dry bias with respect to ERA-Interim is much larger than values with respect to GPS (see Fig. 6b-c). This is not surprising since models in general, including high-resolution regional models (RCM) (e.g. Zeleke et al., 2013) and ERA-Interim in particular, show a wet bias over the high-altitude regions of Ethiopia (Mengistu Tsidu, 2012) likely as a result of the convection scheme.

FTIR observations are limited to daytime when the sun is at a sufficiently high solar zenith angle and the sky is 

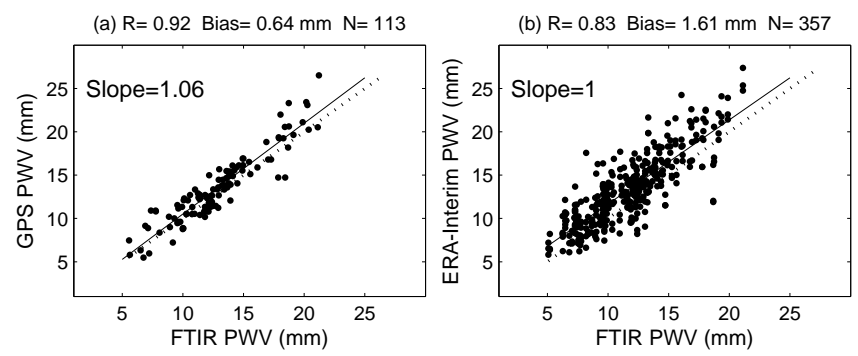

Figure 7. Comparison of GPS-derived and ERA-Interim reanalysis PWV with coincident FTIR measurements.

clear. Moreover, clear sky conditions limit the observation period to be seasonal, with more observations during relatively dry periods. In addition, due to various technical issues, the FTIR observations were not continuous enough even under the above physical limitations. These constraints, together with large gaps in the daily radiosonde observations, led to a situation where coincident FTIR-radiosonde observations within a $1 \mathrm{~h}$ interval are unavailable. On the other hand, since GPS PWV is retrieved at an interval of $2 \mathrm{~h}$ and ERAInterim is given at a temporal resolution of $6 \mathrm{~h}$, it was possible to find coincident FTIR-GPS and FTIR-ERA-Interim measurements as shown in Fig. 7. Despite GPS PWV being retrieved at higher temporal resolution than ERA-Interim, the number of coincident data points between FTIR and ERAInterim is three-fold larger than that of FTIR and GPS observations. This is also attributable to the sizable data gaps in GPS observations in contrast to regular time step of reanalysis data. The correlation between GPS and FTIR PWV is 0.92 with a wet bias of $0.6 \mathrm{~mm}$ in GPS PWV. Previous similar studies at Izaña (Schneider et al., 2010) and Kiruna (Buehler et al., 2012) show a dry bias in GPS as compared to FTIR at lower PWV values. We need to caution that Izaña is generally dry compared to Addis Ababa from comparison of their analysis and our results. The correlation between ERAInterim and FTIR PWV is 0.83 with a wet bias of $1.6 \mathrm{~mm}$ in ERA-Interim. Even though these coincident observations are different from the observations in Fig. 6, there is evidence for a wet bias in ERA-Interim consistently against all observations from other instruments. For example, Fig. 8a shows a wet bias of $4.6 \mathrm{~mm}$ in ERA-Interim PWV with respect to GPS PWV with correlation of 0.85 (see also Table 4).

The comparison of PWV from the three observational data sets and reanalysis model at Addis Ababa implies reasonably good correlation despite a wide range of variation in PWV in the area. The differences are also consistent between the data sets. The error characterization, data quality and consistency of the PWV observations from different instruments and reanalysis can build some level of confidence in the ERA-Interim and GPS data sets from the region far away from Addis Ababa site. The assumption is particularly true for GPS PWV since GPS PWV is derived based on GAMIT network solution involving all sites in the region (see Fig. 1).
This is indeed important to establish since GPS observations and ERA-Interim reanalysis at other sites in the region are the only source of PWV data. The reliability of GPS PWV depends on the availability of surface pressure observations and in the absence of observations on how close the surface pressure from GPT model is to the truth. The surface pressure observations with good-quality flag were used to retrieve GPS PWV wherever possible in spite of large data gaps in the surface pressure observations as well.

\subsection{Comparison of PWV from GPS and ERA-Interim reanalysis at other sites in Ethiopia}

Figure 8 shows the comparison of ERA-Interim and GPS PWV for eight GPS stations for all coincident observations from 2007 to 2011. The GPS data have varying temporal coverage (see Table 2 and Fig. 4). For instance, observations at Mek'ele were taken only in 2008. Observations at Alemaya, Semera and Robe span only 3 years from 2007 to 2009, while observations at Addis Ababa, Nazerate, Bahir Dar and Arba Minch cover the period from 2007 to 2011. Furthermore, the sparsity of data at Addis Ababa, Nazerate, Mek'ele and Bahir Dar is due to the exclusion of observations for which corresponding surface pressure observations are either unavailable or not recommended according to the NOAA NCDC data quality flag.

Figure 8a shows ERA-Interim versus GPS PWV at the Addis Ababa GPS site covering all data for which a correction can be made as a result of available surface pressure observations. The wet bias in ERA-Interim PWV with respect to GPS is higher than values with respect to other instruments as noted in Sect. 3.1 while the correlation is comparable (see also Table 4). The wet bias is throughout the whole range of PWV values with minor enhancement at about $20 \mathrm{~mm}$ GPS PWV values. The general ERA-Interim trend of overestimation over highlands (e.g. at Mek'ele (Fig. 8b), Robe (Fig. 8c), and Alemaya (Fig. 8d)) and underestimation over lowlands (e.g. Arba Minch, Fig. 8e, with the exception of Semera, Fig. 8g) is common. Apart from the topographic features that influence reanalysis, other factors may contribute to the discrepancies. For instance, Bahir Dar is located in the Ethiopian northern highlands where ERA-Interim should have a wet bias. However, as shown in Fig. 8f ERA-Interim shows a dry bias of $4.5 \mathrm{~mm}$ with respect to GPS PWV. Because this difference is larger than the typical GPS uncertainty (see Sects. 2.4 and 3.1) in particular as observed surface pressure is used, the high GPS PWV may be attributed to other factors. Bahir Dar GPS site is located near Lake Tana on its southward side, the largest highland lake in the region. The high evaporation rate from the lake may be responsible for the high PWV detected. This is also the case for Arba Minch GPS site as it is located between two Great Rift Valley lakes (Lake Abaya to the northeast and Lake Chamo to the southwest) and the national park. Moreover, Lake Turkana is located far away on southwestern side of Arba Minch, 
Table 4. Correlation, and enclosed within the bracket are bias (left) and RMSD (right) of PWV between different observations. The sign of the bias is chosen in a way that implies the bias of the first column with respect to the first row.

\begin{tabular}{lcccc}
\hline $\begin{array}{l}\text { Corr } \\
(\text { bias }(\mathrm{mm}), \text { RMSD }(\mathrm{mm}))\end{array}$ & FTIR & GPS & Radiosonde & ERA-Interim \\
\hline FTIR & 1 & $0.92(-0.6,1.6)$ & & $0.83(-1.6,2.8)$ \\
GPS & & 1 & $0.92(0.1,2.5)$ & $0.85(-4.6,5.7)$ \\
Radiosonde & & & 1 & $0.88(-3.2,4.2)$ \\
ERA-Interim & & & & 1 \\
\hline
\end{tabular}
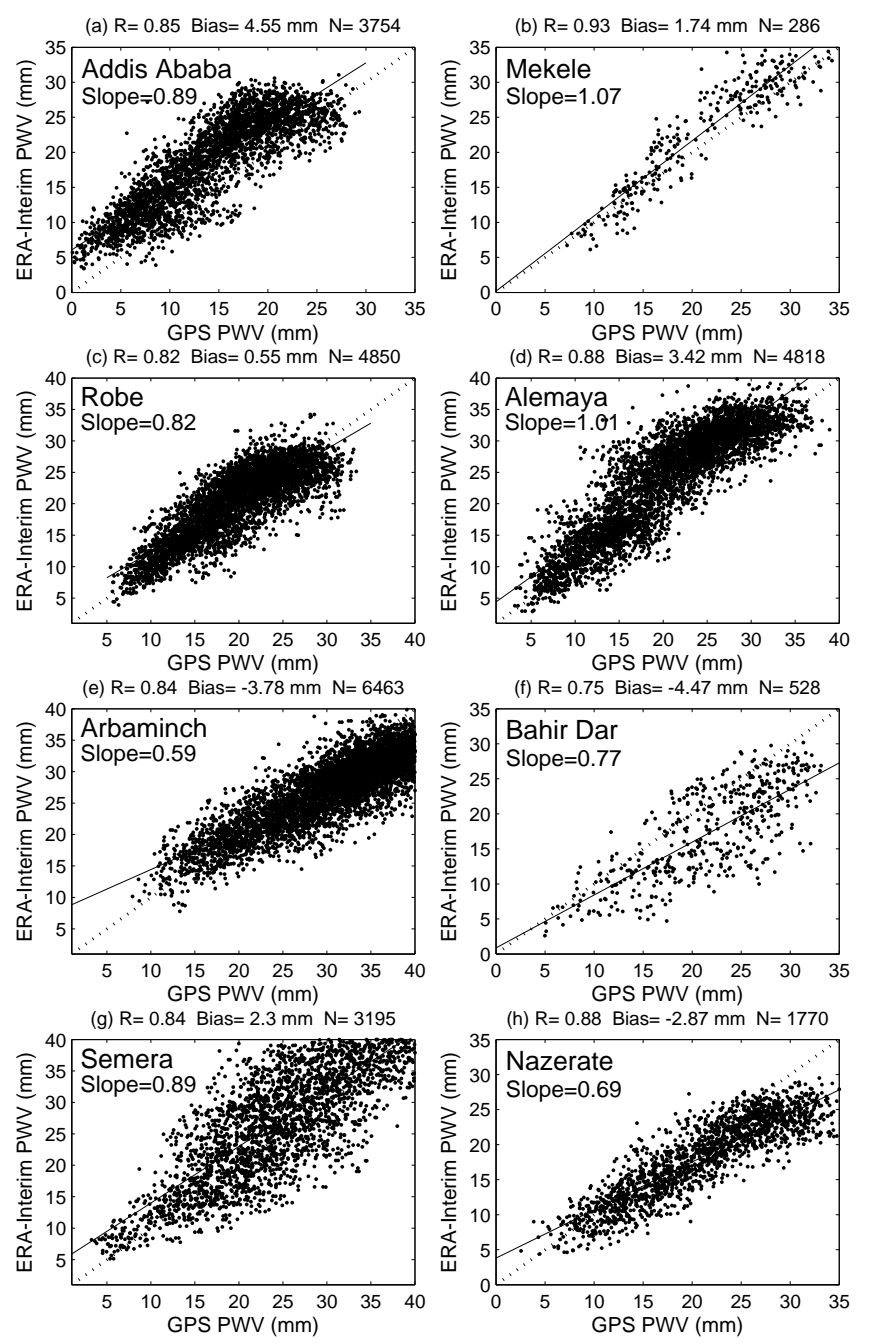

Figure 8. Comparison of GPS and ERA-Interim PWV at eight sites. Each site is shown at the top-left corner of each panel for in Ethiopia. The slope of the solid line from the linear fit is also indicated on each panel.

from which moisture is advected into the southern part of the Ethiopian Rift Valley by the Turkana low-level jet. The boundaries of this lake and others over Ethiopia are shown in Fig. 1b. However, the GPS PWV at Arba Minch is determined using GPT surface pressure and the role of uncer- tainty in GPS PWV due to uncertainty in surface pressure could have some contribution to the overall discrepancies between ERA-Interim and GPS PWV. The impact of using GPT model surface pressure resulted in an offset of $-1.7-2.1 \mathrm{~mm}$ in GPS PWV on average from station to station. As a result, the advantage of using observed surface pressure (in terms of reducing bias, RMSD and strengthening correlation with ERA-Interim PWV) is significant but shows some variations among the GPS sites (Table 5 and also see Sect. 3.1).

Figure 8h shows ERA-Interim versus GPS PWV determined based on surface pressure observations at Nazerate ground GPS receiver site. Normally, a wet bias is expected at Nazerate due to model sensitivity to topography since Nazerate is located on the escarpment of the Great Rift Valley at a height of $1722 \mathrm{~m}$ above sea level. In fact, this was found to be the case from comparison of ERA-Interim precipitation, which exhibits a small wet bias over the Great Rift Valley and adjoining regions as compared to large wet bias over the central Ethiopian highlands (Mengistu Tsidu, 2012). Thus, the dry bias in ERA-Interim reanalysis may not be solely attributed to sensitive convection parameterization and topography in the ECMWF model. To understand why the ERAInterim data exhibit a dry bias at this site with respect to GPS PWV, it is important to understand the climate of Nazerate and surrounding areas. Nazerate is located in the Great Rift Valley regions at the upper Awash river basin, which is characterized by high humidity and temperature as compared to the dry surrounding central highlands of Ethiopia. Moreover, the presence of the Koka dam and sugarcane plantations in the surrounding areas could serve as a source of moisture through direct evaporation and evapotranspiration from the plantations and the forest in Awash National Park. Therefore, the high temperature (not shown) together with these moisture sources could explain why GPS observes higher PWV values than ERA-Interim. Consistent with this, Bock et al. (2005) have also found that the agreement between ERAInterim PWV and GPS PWV over central Europe varies with difference in topography and presence of water body near the GPS sites. The agreement deteriorated as reflected in a decrease in the correlation from 0.92 to 0.89 , an increase in bias and standard deviation (SD) from -1 to $-1.2 \mathrm{~mm}$ and 2.4 to $2.8 \mathrm{~mm}$ on average respectively when only GPS sta- 
Table 5. Summary of correlation, bias, standard deviation and RMSD of ERA-Interim PWV with respect to GPS PWV and the number of data point pairs used in the evaluation of the statistics at the eight GPS stations.

\begin{tabular}{llrrrrr}
\hline Station & Surface pressure type & Corr & Bias $(\mathrm{mm})$ & $\mathrm{SD}(\mathrm{mm})$ & RMSD $(\mathrm{mm})$ & Number of data $^{1}$ \\
\hline Addis Ababa & Observation & 0.85 & 4.6 & 3.4 & 5.7 & 3754 \\
& GPT & 0.83 & 5.5 & 3.1 & 6.3 & 3754 \\
Mek'ele & Observation & 0.93 & 1.7 & 2.9 & 3.4 & 286 \\
& GPT & 0.93 & 3.9 & 2.8 & 4.8 & 286 \\
Robe & GPT & 0.82 & 0.6 & 3.1 & 3.2 & 4850 \\
Alemaya & GPT & 0.88 & 3.4 & 3.8 & 5.1 & 4818 \\
Arba Minch & GPT & 0.84 & -3.8 & 4.1 & 5.6 & 6463 \\
Bahir Dar & Observation & 0.75 & -4.5 & 4.4 & 6.3 & 528 \\
& GPT & 0.74 & -6.2 & 4.6 & 7.7 & 528 \\
Semera & GPT & 0.84 & 2.3 & 5.5 & 6.0 & 3195 \\
Nazerate & Observation & 0.88 & -2.9 & 3.4 & 4.5 & 1770 \\
& GPT & 0.87 & -4.5 & 3.7 & 5.8 & 1770 \\
\hline
\end{tabular}

1 The number of data pairs is also given in Fig. 8.
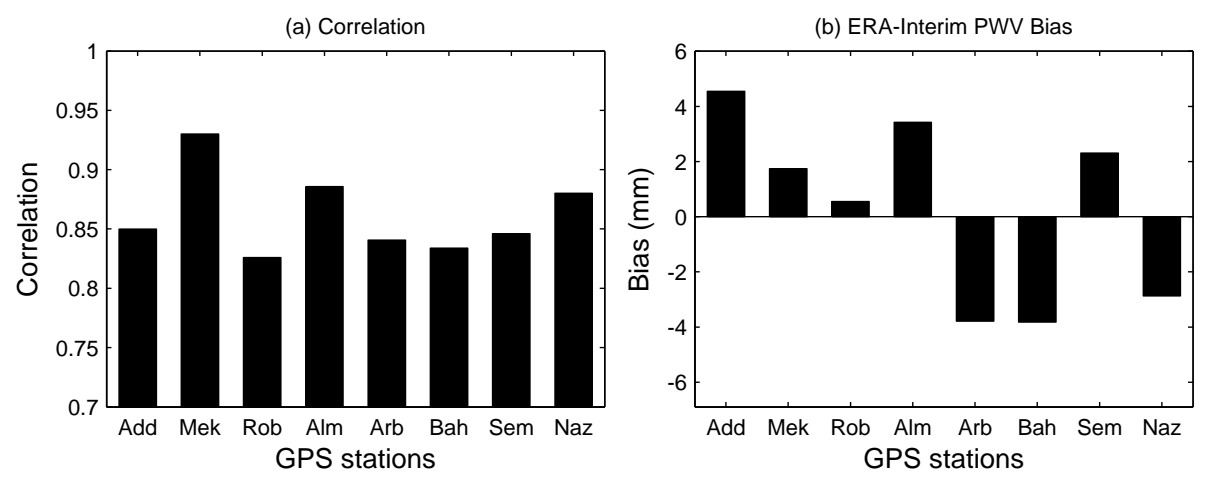

Figure 9. Correlation coefficients of individual observations between ERA-Interim and GPS (a) and bias in ERA-Interim with respect to GPS (b) for all eight ground GPS receiver sites.

tions located over mountain and near sea sites are used to evaluate the statistics.

Figure 9 depicts the correlation (panel a) and bias (panel b) between ERA-Interim and GPS PWV for all eight stations. GPS and ERA-Interim show correlations between 0.75 and 0.93 at the different stations. With the exception of the three GPS sites (Arb, Bah and Naz) discussed above, ERA-Interim shows a wet bias compared to GPS PWV. The bias at individual sites ranges from -4.5 to $4.6 \mathrm{~mm}$ while SD and RMSD vary from 2.9 to $4.4 \mathrm{~mm}$ and 3.2 to $6.3 \mathrm{~mm}$ (Table 5) respectively in contrast to a bias with the range of -4 to $0 \mathrm{~mm}$ over central Europe as reported by Bock et al. (2005). However, such comparison should be carefully interpreted since a number of distinctions (e.g. considerable difference in topography, GPS network density, availability of surface pressure observations, difference in the skill of the ERA-Interim model over different regions) between central Europe and Ethiopia exist. For example, Bock et al. (2007a) have found agreement between ERA-40 and GPS PWV over scattered GPS sites over Africa with standard deviation of $2.5-4.5 \mathrm{~mm}$ emphasizing the role of the above factors. In addition, recent study (Bollmeyer et al., 2015) over almost the same European domain has shown the added value of data assimilation over dynamical downscaling as exhibited by RMSD of $2 \mathrm{~mm}$ in PWV obtained from models with dynamical downscaling plus data assimilation, $2.5 \mathrm{~mm}$ from ERA-Interim and $4 \mathrm{~mm}$ from dynamical downscaling without data assimilation from GPS PWV. The observed advantage of data assimilation over downscaling in this case strengthens the assertion that the large bias and RMSD observed over Ethiopia are partly attributable to poor skill of the model in conjunction with lack of data or sparse data assimilated in ERA-Interim.

\subsection{Diurnal and seasonal variability of ERA-Interim and GPS PWV}

The variation in biases in ERA-Interim PWV with respect to GPS PWV due to local features, such as proximity of GPS sites to water bodies and natural vegetation, and sensitivity of model convection schemes to topography have so far been discussed. However, there is also a possibility that other factors (e.g. the land module scheme in GCM and 

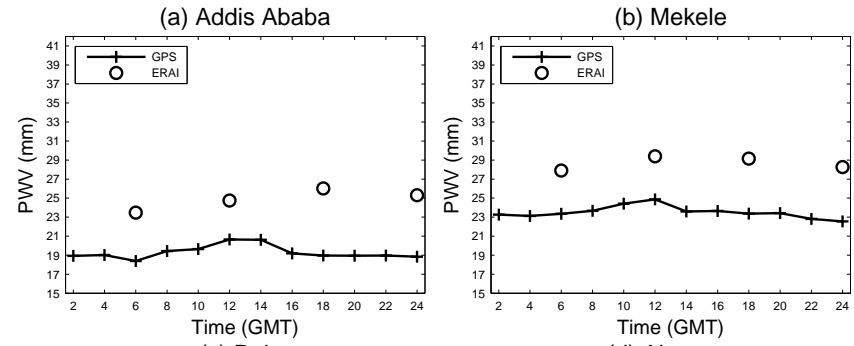

(c) Robe

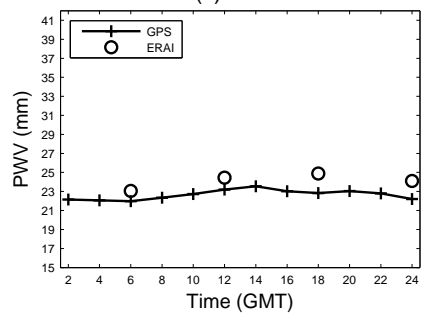

(e) Arbaminch

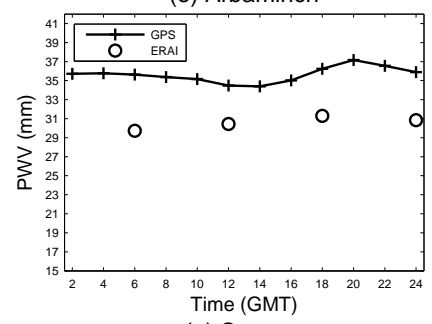

(g) Semera
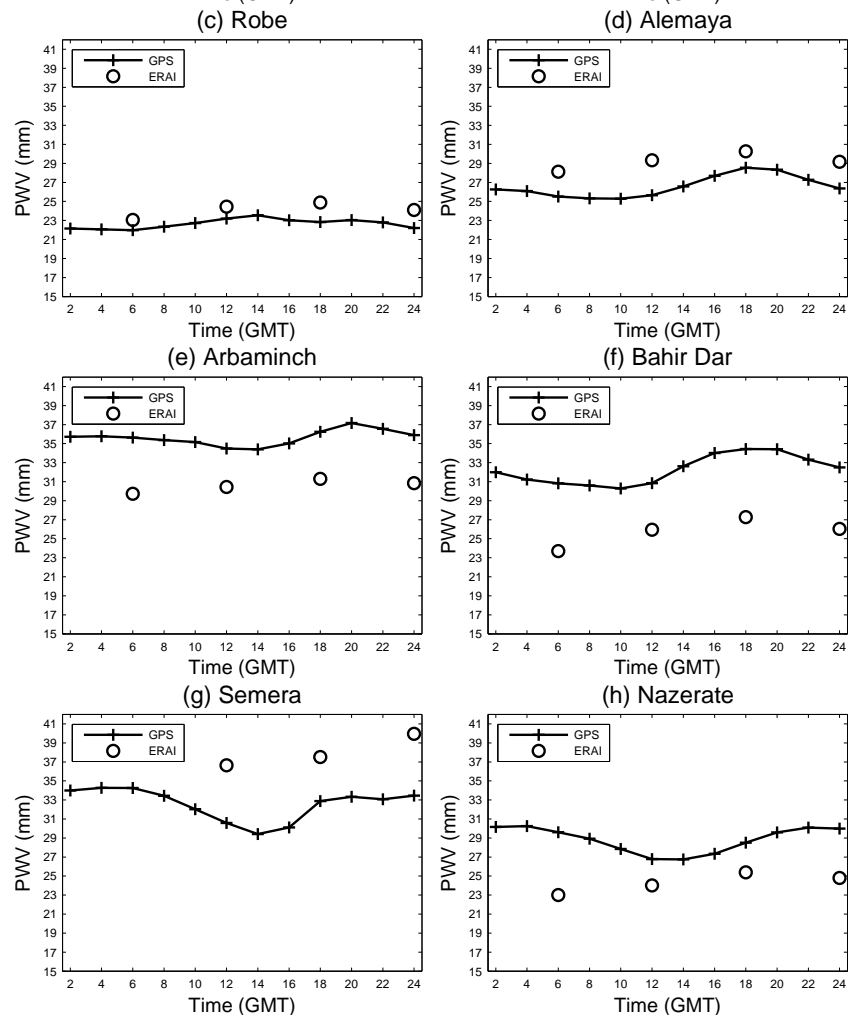

(f) Bahir Dar

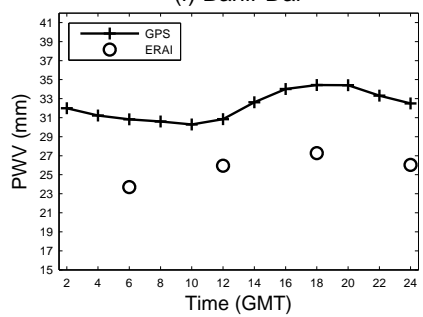

(h) Nazerate

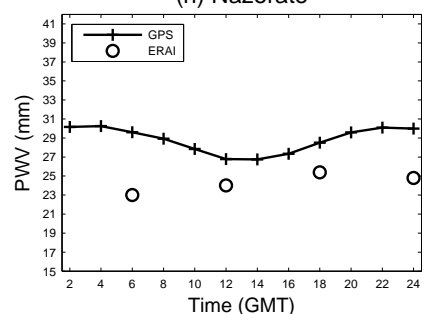

Figure 10. The diurnal cycles of GPS and ERA-Interim PWV at all GPS ground receiver sites during summer.

RCM) could also impact PWV estimates. All these factors are expected to show marked seasonal variability, implying that ERA-Interim exhibits similar features. Moreover, the performance of the reanalysis can also be assessed with respect to its skill in capturing diurnal variability exhibited by GPS PWV. Figure 10 shows diurnal cycles of ERA-Interim and GPS PWV at all GPS ground receiver sites during summer. The PWV at highland GPS sites (e.g. Addis Ababa, Mek'ele, Robe) peaks before noon from 12:00 to 14:00 GMT (09:11 LT) in contrast to GPS sites in the Great Rift Valley region (Arba Minch, Semera, Nazerate) and near lake (e.g. Bahir Dar), which attain a maximum during late afternoon to evening from 18:00 to 22:00 GMT (15:00-19:00 LT). The PWV observation over the highland GPS station at Alemaya exhibits a similar peak in the late afternoon. Solar insolation controls the surface energy budget and therefore evapotranspiration, which in turn depends on available water re-
Table 6. Dominant surface types within $50 \mathrm{~km}$ radius of the eight GPS stations obtained from MODIS $0.5 \times 0.5 \mathrm{~km}$ resolution data (Broxton et al., 2014).

\begin{tabular}{ll}
\hline Station & Dominant surface type \\
\hline Addis Ababa & $\begin{array}{l}\text { croplands/natural vegetation mosaic } \\
\text { open shrublands } \\
\text { Mek'ele }\end{array}$ \\
Robe & croplands/natural vegetation mosaic \\
Alemaya & Grasslands \\
Arba Minch & lakes, woody savannas \\
Bahir Dar & lake, open shrublands \\
Semera & closed shrublands to southwest; \\
& barren lands to northeast \\
Nazerate & lakes to southwest, grass/croplands \\
\hline
\end{tabular}

sources in vegetation and open water bodies. For instance, the difference between PWV diurnal cycle at Alemaya and the other highland GPS sites might be linked to difference in topography and land surface types. The similarity in surface types among some GPS sites given in Table 6 is nearly in line with observed similar diurnal cycles of PWV among sites described above. The highlands, with exception of Alemaya with grasslands, possess croplands/natural vegetation mosaic and open shrublands which have a moderate evapotranspiration (Wang et al., 2012; Slazek, 2014). Moreover, the similarity between the observed diurnal PWV variability at Alemaya, with dominant grass surface characterized by high evapotranspiration, and other sites, with proximity to lakes, is also consistent with high PWV from these sites. Bock et al. (2007b) have also observed differences in time of occurrence of the peak PWV between GPS sites over Africa and have attributed them to various factors ranging from difference in local breeze circulations to ocean and continental processes. In contrast, ERA-Interim PWV does not seem to capture the observed diurnal cycle in GPS PWV as exhibited by a shift in the time of peak PWV at nearly all sites with the exception of Bahir Dar and Alemaya. Bock et al. (2011) have also found that ERA-Interim and other reanalysis data sets have failed to capture diurnal cycle observed in mean of PWV from seven GPS sites over western Africa while the agreement at longer temporal scales (e.g. season, annual mean) was good.

The minimum amplitude of the diurnal cycle (i.e. $1 \mathrm{~mm}$ ) is observed at Robe GPS site while the amplitude at the two highlands stations, Addis Ababa and Mek'ele, is approximately $2 \mathrm{~mm}$. The maximum amplitude of diurnal cycle of PWV (about $6 \mathrm{~mm}$ ) is observed at Semera followed by Bahir Dar (approx. $4.5 \mathrm{~mm}$ ) and Nazerate $(3.5 \mathrm{~mm})$.

Figure 11 shows the correlation and bias of ERA-Interim PWV with respect to GPS PWV for spring (MAM) (panels a-b), summer (JJA) (panels c-d), autumn (SON) (panels e-f) and winter (DJF) (panels $\mathrm{g}-\mathrm{h}$ ). The correlation coefficients between ERA-Interim and GPS are generally good, on the order of 0.8 or greater for most sites during MAM, SON and 

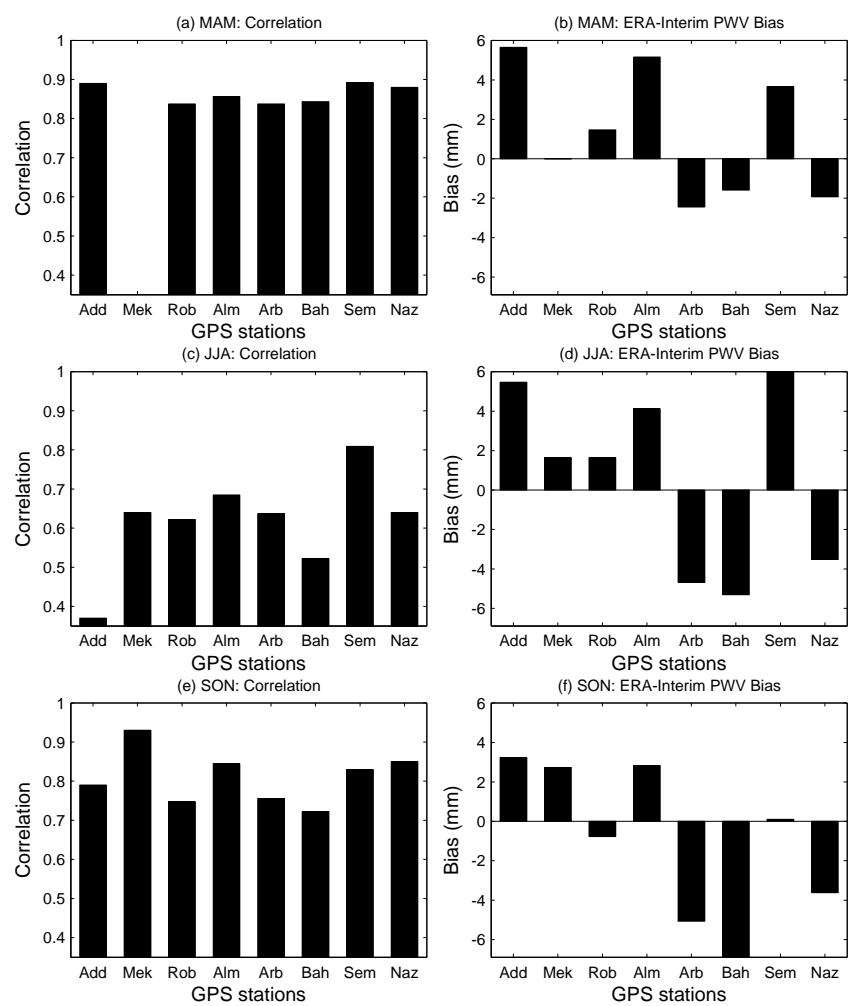

GPS stations
(g) DJF: Correlation
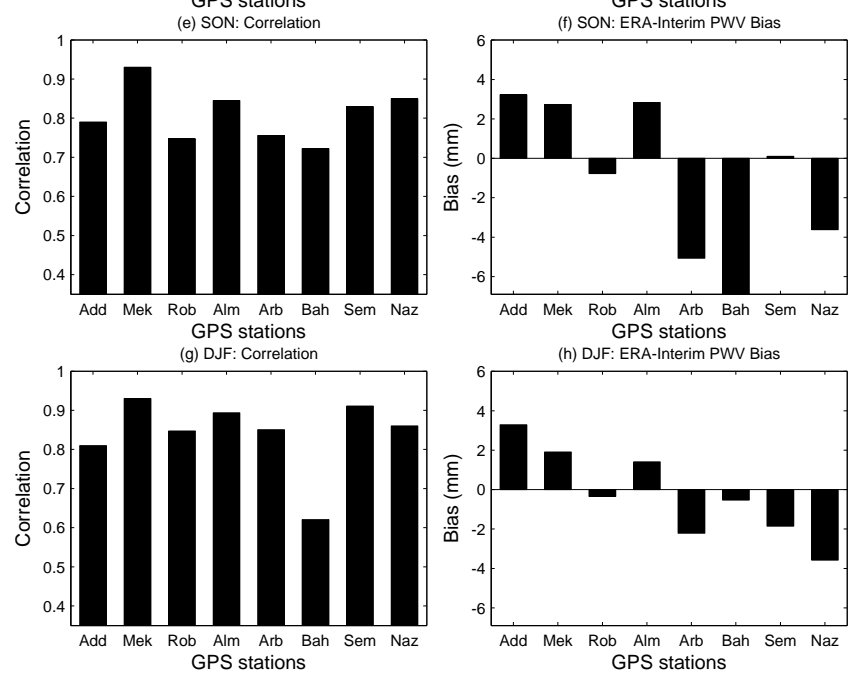

(h) DJF: ERA-Interim PWV Bias

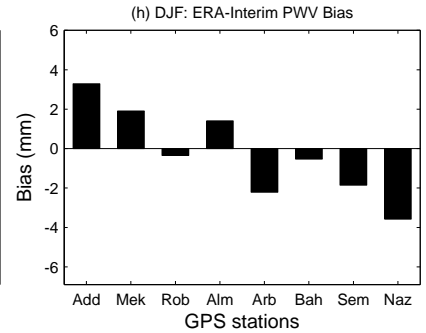

Figure 11. The same as Fig. 9 for ERA-Interim versus GPS but separated into seasons: MAM (a-b), JJA (c-d), SON (e-f) and DJF (gh).

DJF. Moreover, the southern half of the country gets moderate rainfall during MAM and SON. In contrast, the correlations during the wet and warm JJA summer season are mostly lower than 0.8. This implies a deficiency in the ERA-Interim model convection scheme as indicated earlier since convection is the main source of moisture in the atmosphere. This line of reasoning is also consistent with wet bias (as shown in left panels of Fig. 11) in JJA for five of the eight GPS sites. While the seasonal variation in PWV is externally forced due to the solar cycle as captured correctly by both ERA-Interim and GPS (see Fig. 12), the level of agreement between the two data sets is mainly driven by the model skill in addition to the role of local features discussed in Sect. 3.2.

The seasonal cycles (Fig. 12) are well captured by all data sets. The broad PWV maximum at most GPS sites from March to October is consistent with broad observed solar insolation for Ethiopian latitude range. In contrast, Semera
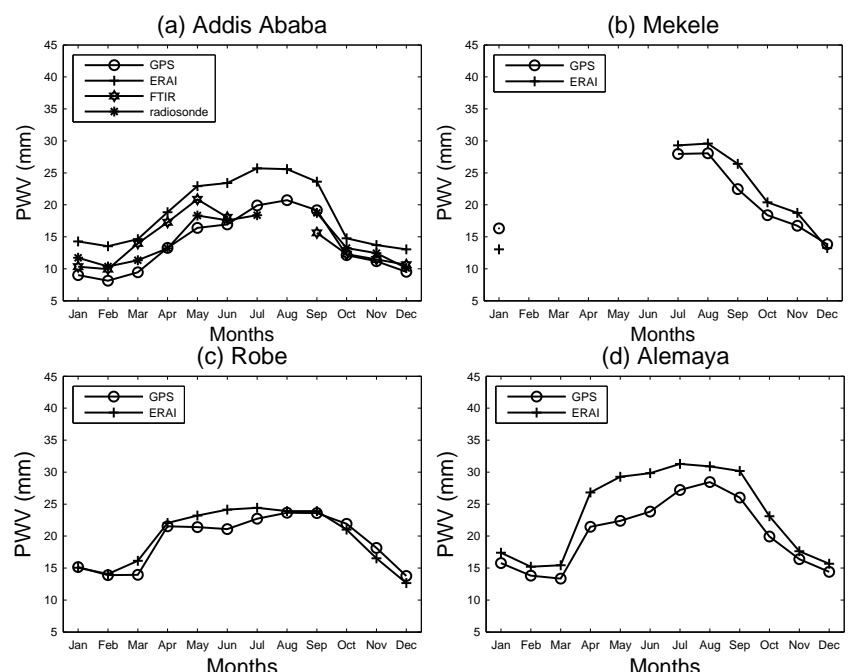

(d) Alemaya

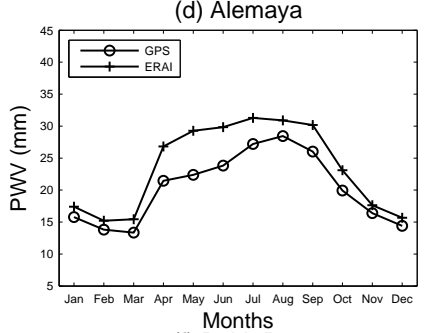

(e) Arbaminch
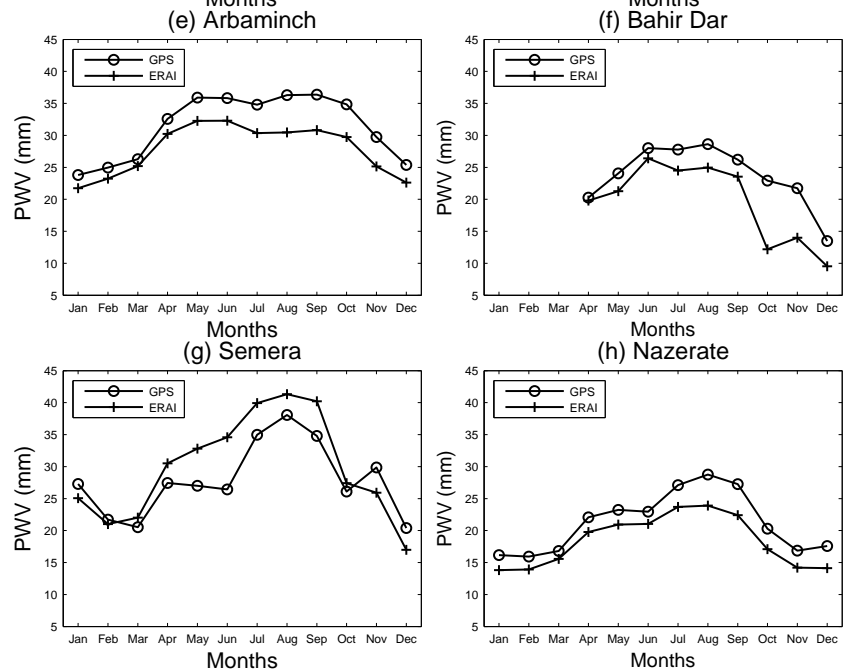

Figure 12. The seasonal water vapour cycle as captured by different data sets at Addis Ababa (a), and by ERA-Interim and GPS at the remaining seven GPS sites (b-h).

and Nazerate have relatively pronounced PWV peaks in both GPS and ERA-Interim observations during JJA. What is perhaps important to note on the seasonal basis is the presence of a large discrepancy between ERA-Interim and GPS PWV in most of the wet months from May to September. In contrast, the agreement improves during relatively dry months, which is also evident from lowest RMSD of $2.2 \mathrm{~mm}$ at Robe in DJF and highest RMSD of $8.0 \mathrm{~mm}$ at Semera in JJA.

The role of local features, such as the proximity to moisture sources and variability in the extent of this influence from season to season, can be further appreciated from inspection of the vertically integrated moisture flux shown in Fig. 13. Figure 13 shows seasonal mean vertically integrated moisture flux (vectors) and PWV (colour contours) from ERA-Interim for the 2007-2011 period of our investigation. The ERA-Interim PWV (colour contours) for all seasons shows generally dry Ethiopian highlands, wet low- 
(a) MAM

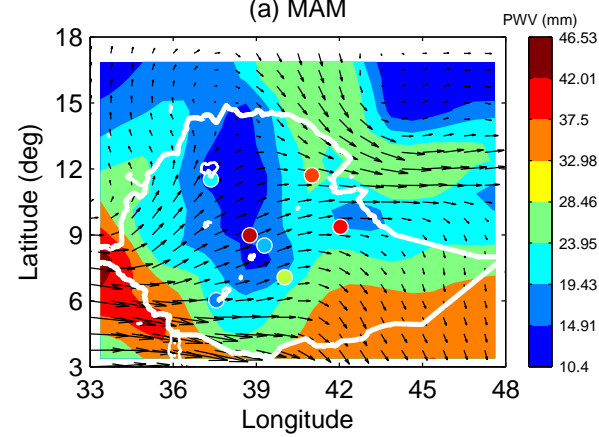

(c) SON

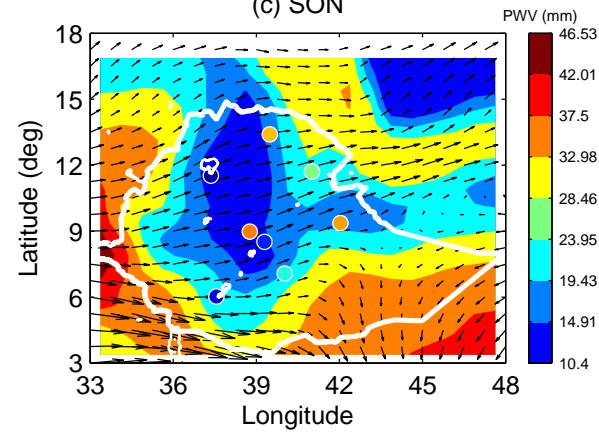

(b) JJA

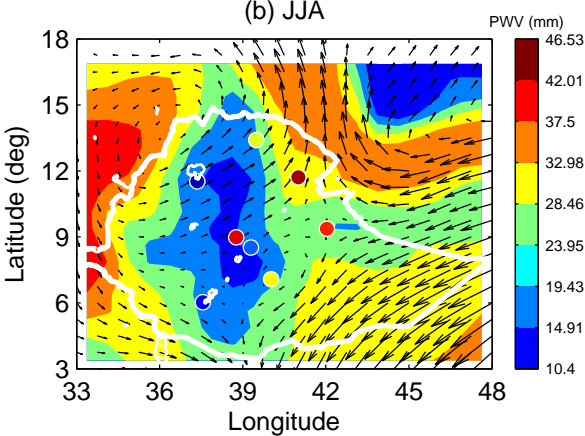

(d) DJF

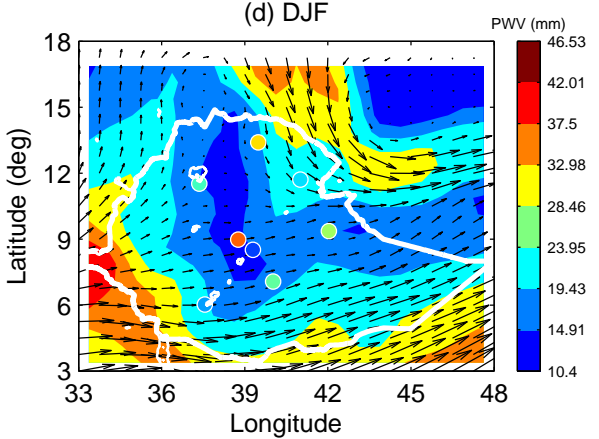

Figure 13. The ERA-Interim PWV (colour contours), and vertically integrated (to $500 \mathrm{hPa}$ ) moisture flux (vectors) over the study region. The circle, filled with different colours according to ERA-Interim PWV bias with respect to GPS PWV (i.e. from highest negative bias (-6.9 mm) in blue to highest positive bias in dark red $(6.0 \mathrm{~mm})$ for all seasons on the same scale; See also Fig. 11), represents the eight GPS sites and the white solid line represents the boundary of Ethiopia.

lands in the west and south of the country, as well as wet Red Sea and adjoining areas in the northeast. However, there are some differences in both the seasonal mean PWV and direction of moisture transport from one season to the other. Since the moisture flux is vertically integrated up to $500 \mathrm{hPa}$, this could represent moisture transport in the lower troposphere. For example, most of the GPS stations, with exception of Mek'ele and Semera in the north and northeast, are under the influence of westerly and southwesterly vertically integrated moisture flux during MAM as shown in Fig. 13a. The southwestern part of Ethiopia lying west of these GPS sites receives rainfall during MAM, JJA, and SON (Mengistu Tsidu, 2012). Moreover, the region is covered by relatively dense evergreen broad-leaf forest (also visible in the recent $0.5 \mathrm{~km}$ resolution MODIS land cover data (Broxton et al., 2014), not shown). This suggests that all of the GPS sites, with the exception of Mek'ele and Semera in the far north and northeast, receive moisture from this part of the country and the adjacent lakes due to the prevailing winds during MAM and SON as shown in Fig. 13a and c. The southwestern Ethiopian lowlands and adjoining eastern South Sudan are also a source of moisture for the southern half of the country in DJF (see Fig. 13d).

In JJA, the moisture source in the southwestern Ethiopian lowlands and adjoining eastern South Sudan shifted slightly towards the northwest of the country, implying that the GPS sites in the northern part of the country should benefit from
Table 7. The seasonal mean PWV (mm) and standard deviation $(\mathrm{mm})$ in brackets as determined from the eight ground-based GPS receivers used in this study.

\begin{tabular}{lcccc}
\hline Station & MAM & JJA & SON & DJF \\
\hline Addis Ababa & $18.5(5.5)$ & $25.0(3.5)$ & $19.8(5.8)$ & $15.5(4.5)$ \\
Mek'ele & - & $24.7(3.3)$ & $17.2(5.4)$ & $11.5(2.9)$ \\
Robe & $19.6(5.1)$ & $22.5(3.7)$ & $21.2(5.3)$ & $14.7(4.0)$ \\
Alemaya & $19.7(6.5)$ & $26.5(4.2)$ & $20.7(7.0)$ & $14.9(5.4)$ \\
Arba Minch & $32.0(6.7)$ & $35.6(4.4)$ & $33.4(6.6)$ & $25.5(7.2)$ \\
Bahir Dar & $22.1(6.7)$ & $32.3(3.9)$ & $26.4(6.5)$ & $16.9(4.3)$ \\
Semera & $25.4(9.9)$ & $31.8(8.7)$ & $29.7(8.9)$ & $24.1(8.4)$ \\
Nazerate & $23.5(7.0)$ & $29.0(4.2)$ & $24.0(7.1)$ & $19.4(5.8)$ \\
\hline
\end{tabular}

the local moisture source due to convective rainfall (see Fig. 13b). The Red Sea region also serves as a moisture source during MAM (Fig. 13a) and DJF (Fig. 13d) as indicated by northerly and northwesterly moisture flux vectors. This is also evident from the GPS observations (see Table 7) that exhibit high PWV for Semera during these seasons as compared to other sites, with the exception of Arba Minch. This is in clear contrast to PWV from ERA-Interim reanalysis which captures broad features due to topographic differences but not localized differences between GPS sites that arise due to proximity to water mass and vegetation cover (see Sect. 3.2) as revealed in GPS observations. 


\section{Conclusions}

The quality and consistency of different observational and reanalysis PWV data sets are investigated, and the different error sources impacting the data taken over Addis Ababa are characterized. Upon establishing confidence in the reliability and robustness of the data from this investigation, the analysis is extended to include seven other GPS sites using GPS and ERA-Interim PWV. This effort is aimed at filling the observational data and knowledge gaps regarding water vapour variability in this part of the globe for the first time.

The PWV from FTIR, GPS and radiosondes is characterized in terms of different sources of error. The propagated uncertainty from statistical and systematic formal retrieval error in FTIR observations is found to be very small (i.e. approximately $0.5 \mathrm{~mm}$ on average). The sensitivity of GPS PWV to uncertainty in TZD, surface pressure and surface temperature has been estimated. The $4 \mathrm{~mm}$ error in TZD, $1.3 \mathrm{~K}$ error in atmospheric temperature and $1.65 \mathrm{hPa}$ error in surface pressure can lead to $1.32 \mathrm{~mm}$ error in PWV, which is within the maximum formal least squares solution error of $2 \mathrm{~mm}$. The relative humidity measured by the RS92 radiosonde capacitive sensor is known to suffer from the solar radiation dry bias, which applies to Addis Ababa radiosondes as reflected by the PWV dry bias with respect to ERA-Interim and GPS. On average, the estimated solar radiation dry bias in radiosonde PWV is $0.51 \pm 0.18 \mathrm{~mm}$, which can explain the observed systematic difference of radiosonde PWV from GPS. However, this value is much less than the observed difference between the radiosonde and ERA-Interim PWV, suggesting other factors than solar radiation dry bias primarily linked with model skill.

In addition to the assessment of the impact of uncertainty in surface pressure on PWV, the impact of use of the GPT model rather than measured pressure is evaluated at four GPS sites. The effect on PWV varies between -1.7 and $+2.1 \mathrm{~mm}$ from station to station on average. As a result, the use of observed surface pressure reduces the bias and the RMSD as well as strengthens the correlation with ERA-Interim PWV although with some variations among the GPS sites. The variable benefit of using measured surface pressure among GPS sites is linked to the variation in the skill of the GPT model for different parts of the country and underlines the importance of surface pressure observations for GPS measurements of PWV.

The comparison between ERA-Interim and GPS PWV shows differences in the magnitude and sign of bias of ERAInterim PWV with respect to GPS PWV from station to station. This difference in the relationship between the two data sets from station to station is also visible across different seasons and in diurnal PWV variability. The cause of these differences is linked to variation in model skill over different regions, seasons and time of the day. The model convection scheme appears to be sensitive to topography as reflected in the generally wet bias over highlands and dry bias over lowlands. This general tendency is consistent with previous studies on precipitation. However, there are also other factors such as the land surface module in the model and land surface features including land cover type and proximity to water bodies. For instance, evaporation at Lake Tana near the northern highland GPS station at Bahir Dar might cause the wet bias in GPS PWV with respect to ERA-Interim contrary to the general tendency of high precipitation and PWV in ERAInterim over highlands. This is also the case at Arba Minch GPS station located between two lakes. The skill of ECMWF in reproducing realistic PWV (i.e. as characterized by good agreement with GPS PWV) varies with season, showing a large bias during wet summer and dry winter months. Good agreement, as characterized by the correlation between GPS and ERA-Interim PWV, is achieved during spring (MAM), autumn (SON) and winter (DJF) at all stations.

In general ERA-Interim captures the seasonal PWV variability well albeit with spatial differences in the model performance when compared to GPS. This weakness is also apparent in PWV diurnal variability, implying the need for further improvement in ERA-Interim through additional data assimilation, adaptation of the convection and land surface module schemes to the reality in the region.

Acknowledgements. The authors acknowledge NOAA NCDC for radiosonde and surface pressure data, UNAVCO for installation, maintenance and free access to GPS data, and ECMWF for access to ERA-Interim data sets. The first author would also like to acknowledge the financial support of the Humboldt foundation through the author's Humboldt fellowship grant during which this work is accomplished. We acknowledge support by Deutsche Forschungsgemeinschaft and Open Access Publishing Fund of the Karlsruhe Institute of Technology. The authors acknowledge the two anonymous reviewers and the handling editor, Kimberly Strong, for their useful comments and suggestions, which have improved the quality of the manuscript.

The article processing charges for this open-access publication were covered by a Research Centre of the Helmholtz Association.

Edited by: K. Strong

\section{References}

Agusti-Panareda, A., Vasiljevic, D., Beljaars, A., Bock, O., Guichard, F., Nuret, M., Mendez, A. G., Andersson, E., Bechtold, P., Fink, A., Hersbach, H., Lafore, J.-P., Ngamini, J.-B., Parker, D. J., Redelsperger, J.-L., and Tomkins, A. M.: Radiosonde humidity bias correction over the West African region for the special AMMA reanalysis at ECMWF, Q. J. Roy. Meteorol. Soc., 135, 595-617, doi:10.1002/qj.396, 2009.

Auligne, T., McNally, A., and Dee, D.: Adaptive bias correction for satellite data in a numerical weather prediction system, Q. J. Roy. Meteorol. Soc., 133, 631-642, 2007. 
Berrisford, P., Dee, D., Fielding, K., Fuentes, M., Kollberg, P., Kobayashi, S., and Uppala, S.: The ERA-Interim archive Version 1.0 Series: ERA Report Series, ECMWF, Shinfield Park, Reading, Berkshire RG2 9AX, UK, 2009.

Bevis, M., Businger, S., Herring, T. A., Rocken, C., Anthes, R. A., and Ware, R. H.: GPS meteorology-Remote-sensing of atmospheric water-vapor using the Global Positioning System, J. Geophys. Res., 97, 15787-15801, 1992.

Bevis, M., Businger, S., Chiswell, S., Herring, T. A., Anthes, R. A., Rocken, C., and Ware, R. H.: GPS meteorology-Mapping zenith wet delays onto precipitable water, J. Appl. Meteorol., 33, 379_ 386, 1994.

Bock, O., Keil, C., Richard, E., Flamant, C., and Bouin, M.-N.: Validation of precipitable water from ECMWF model analyses with GPS and radiosonde data during the MAP SOP, Q. J. Roy. Meteorol. Soc., 131, 3013-3036, doi:10.1256/qj.05.27, 2005.

Bock, O., Bouin, M. N., Walpersdorf, A., Lafore, J. P., Janicot, S., Guichard, F., and Agusti-Panareda, A.: Comparison of groundbased GPS precipitable water vapour to independent observations and NWP model reanalyses over Africa, Q. J. Roy. Meteorol. Soc., 133, 2011-2027, 2007a.

Bock, O., Guichard, F., Janicot, S., Lafore, J. P., Bouin, M.-N., and Sultan, B.: Multiscale analysis of precipitable water vapor over Africa from GPS data and ECMWF analyses, Geophys. Res. Lett., 34, 2007b.

Bock, O., Bouin, M. N., Doerflinger, E., Collard, P., Masson, F., Meynadier, R., Nahmani, S., Koité, M., Gaptia Lawan Balawan, K, Didé, F., Ouedraogo, D., Pokperlaar, S., Ngamini, J.B., Lafore, J. P., Janicot, S., Guichard, F., and Nuret, M.: West African Monsoon observed with ground-based GPS receivers during African Monsoon Multidisciplinary Analysis (AMMA), J. Geophys. Res., 113, 1-53, 2008.

Bock, O., Willis, P., Lacarra, M., and Bosser, P.: An intercomparison of zenith tropospheric delays derived from DORIS and GPS data, Adv. Space Res., 46, 1648-1660, 2010.

Bock, O., Guichard, F., Meynadier, R., Gervois, S., AgustiPanareda, A., Beljaars, A., Boone, A., Nuret, M., Redelsperger, J.-L., and Roucou, P.: The large-scale water cycle of the West African monsoon, Atmosph. Sci. Lett., 12, 51-57, doi:10.1002/asl.288, 2011.

Boehm, J., Heinkelmann, R., and Schuh, H.: Short note: a global model of pressure and temperature for geodetic applications, J. Geod., 81, 679-683, 2007.

Bollmeyer, C., Keller, J., Ohlwein, C., Bentzien, S., Crewell, S., Friedrichs, P., Hense, A., Keune, J., Kneifel, S., Pscheidt, I., Redl, S., and Steinke, S.: Towards a high-resolution regional reanalysis for the European CORDEX domain, Q. J. Roy. Meteorol. Soc., 141, 1-15, doi:10.1002/qj.2486, 2015.

Braun, J., Rocken, C., and Liljegren, C.: Comparisons of line-ofsight water vapor observations using the global positioning system and a pointing microwave radiometer, J. Atmos. Ocean. Technol., 20, 606-612, 2003.

Broxton, P., Zeng, X., Sulla-Menashe, D., and Troch, P.: A Global Land Cover Climatology Using MODIS Data, J. Appl. Meteor. Climatol., 53, 1593-1605, doi:10.1175/JAMC-D-130270.1, 2014.

Buehler, S. A., Östman, S., Melsheimer, C., Holl, G., Eliasson, S., John, V. O., Blumenstock, T., Hase, F., Elgered, G., Raffalski, U., Nasuno, T., Satoh, M., Milz, M., and Mendrok, J.: A multi- instrument comparison of integrated water vapour measurements at a high latitude site, Atmos. Chem. Phys., 12, 10925-10943, doi:10.5194/acp-12-10925-2012, 2012.

Champollion, C., Masson, F., M.-N. Bouin and, A. W., Doerflinger, E., Bock, O., and Baelene, J. V.: GPS water vapour tomography: preliminary results from the ESCOMPTE field experiment, Atmos. Res., 74, 253-274, 2005.

Combrink, A., Combrinck, W., and Moraal, H.: Near real-time detection of atmospheric water vapour using the SADC GPS network, S. Afr. J. Sci., 100, 436-442, 2004.

Dai, A., Wang, J., Ware, R. H., and van Hove, T.: Diurnal variation in water vapor over North America and its implications for sampling errors in radiosonde humidity, J. Geophys. Res., 107, 4090, doi:10.1029/2001JD000642, 2002.

Dee, D., Uppala, S., Simmons, A., Berrisford, P., ., Poli, P., Kobayashi, S., Andrae, U., Balmaseda, M. A., Balsamo, G., Bauer, P., Bechtold, P., Beljaars, A. C. M., van de Berg, L., Bidlot, J., Bormann, N., Delsol, C., Dragani, R. , Fuentes, M. , Geer, A. J. , Haimberger, L. , Healy, S. B., Hersbach, H., Hólm, E. V., Isaksen, L., Kållberg, P., Köhler, M., Matricardi, M., McNally, A. P., Monge-Sanz, B. M., Morcrette, J.-J., Park, B.-K., Peubey, C., de Rosnay, P., Tavolato, C., Thépaut, J.-N., and Vitart, F.: The ERA-Interim reanalysis: configuration and performance of the data assimilation system, Q. J. Roy. Meteorol. Soc., 137, 553597, doi:10.1002/qj.828, 2011.

Dietrich, S. V. R., Johnsen, K.-P., Miao, J., and Heygster, G.: Comparison of tropospheric water vapour over Antarctica derived from AMSU-B data, ground-based GPS data and the NCEP/NCAR reanalysis, J. Meteorol. Soc. Jpn., 82, 259-267, 2004.

Durre, I., Vose, S. R., and Wuertz, D. B.: Overview of the Integrated Global Radiosonde Archive, J. Climate, 19, 53-68, 2006.

Echle, G., von Clarmann, T., Dudhia, A., Flaud, J.-M., Funke, B., Glatthor, N., Kerridge, B., Lopez-Puertas, M., Martin-Torres, F. J., and Stiller, G. P.: Optimized spectral microwindows for data analysis of the Michelson Interferometer for Passive Atmospheric Sounding on the Environmental Satellite, Appl. Opt., 39, 5531-5540, 2000.

Fetzer, E., McMillin, L. M., Tobin, D., Aumann, H. H., Gunson, M. R., McMillan, W. W., Hagan, D. E., Hofstadter, M. D., Yoe, J., Whiteman, D. N., Barnes, J. E., Bennartz, R., Vomel, H., Walden, V., Newchurch, M., Minnett, P. J., Atlas, R., Schmidlin, F., Olsen, E. T., Goldberg, M. D., Zhou, S. S., Ding, H. J., Smith, W. L., and Revercomb, H.: AIRS/AMSU/HSB Validation, IEEE Trans. Geosci. Remote Sens., 41, 418-431, 2003.

Ge, M., Calais, E., and Haase, J.: Sensitivity of zenith total delay accuracy to GPS orbit errors and implications for near-realtime GPS meteorology, J. Geophys. Res., 107, ACL 12-1-12-15, doi:10.1029/2001JD001095, 2002.

Gendt, G., Dick, G., Reigber, C., Tomassini, M., Liu, Y., and Ramatschi, M.: Near real time GPS water vapor monitoring for numerical weather prediction in Germany, J. Meteorol. Soc. Jpn., 82, 361-370, 2004.

Gradinarsky, L. P., Johansson, J. M., Bouma, H. R., Scherneck, H.G., and Elgered, G.: Climate monitoring using GPS, Phys. Chem. Earth, 27, 335-340, 2002.

Guerova, G., Brockmann, E., Quiby, J., Schubiger, F., and Matzler, C.: Validation of NWP mesoscale models with Swiss GPS network AGNES, J. Appl. Meteorol., 42, 141-150, 2003. 
Hase, F., Blumenstock, T., and Paton-Walsh, C.: Analysis of the instrumental line shape of high-resolution Fourier transform IR spectrometers with gas cell measurements and new retrieval software, Appl. Opt., 38, 3417-3422, 1999.

Jin, S. and Park, P. H.: A new precision improvement in zenith tropospheric delay estimation by GPS, Curr. Sci., 89, 997-1000, 2005.

King, M. D., Menzel, W. P., Kaufman, Y. J., Tanré, D., Gao, B.C., Platnick, S., Ackerman, S. A., Remer, L. A., Pincus, R., and Hubanks, P. A.: Cloud and Aerosol Properties, Precipitable Water, and Profiles of Temperature and Water Vapor from MODIS, IEEE Trans. Geosci. Remote Sens., 41, 442-458, 2003.

King, R. and Bock, Y.: Documentation of the GAMIT GPS Analysis Software, Release 10.3 Edition, Massachusetts Institute of Technology and Scripts Institution of Oceanography, University of California, San Diego, CA, USA, 2006.

Koulali, A., Ouazar, D., Bock, O., and Fadil, A.: Study of seasonalscale atmospheric water cycle with ground-based GPS receivers, radiosondes and NWP models over Morocco, Atmos. Res., 104105, 273-291, doi:10.1016/j.atmosres.2011.11.002, 2011.

Mears, C., Santer, B. D., Wentz, F. J., Taylor, K., and Wehner, M.: Relationship between temperature and precipitable water changes over tropical oceans, Geophys. Res. Lett., 34, L24709, doi:10.1029/2007GL031936, 2007.

Mengistu Tsidu, G.: Determination of optimized microwindows for analysis of absorption spectra from ground-based FTIR spectrometer, MSc thesis, Addis Ababa University, Addis Ababa, Ethiopia, 1998.

Mengistu Tsidu, G.: High-Resolution Monthly Rainfall Database for Ethiopia: Homogenization, Reconstruction, and Gridding, J. Climate, 25, 8422-8443, 2012.

Miloshevich, L. M., Paukkunen, A., Vomel, H., and Oltmans, S. J.: Development and Validation of a Time-Lag correction for Vaisala Radiosonde Humidity Measurements, J. Atmos. Oceanic Technol., 21, 1305-1327, 2004.

Miloshevich, L. M., Vomel, H., Whiteman, D., Lesht, B., Schmidlin, F., and Russo, F.: Absolute accuracy of water vapor measurements from six operational radiosonde types launched during AWEX-G and implication of AIRS validation, J. Geophys. Res., 111, D09S10, doi:10.1029/2005JD006083, 2006.

Ning, L., Trenberth, K. E., Qin, J., Yang, K., and Yao, L.: Detecting Long-Term Trends in Precipitable Water over the Tibetan Plateau by Synthesis of Station and MODIS Observations, J. Climate, 28, 1707-1722, doi:10.1175/JCLI-D-14-00303.1, 2015.

Ning, T., Elgered, G., Willen, U., and Johansson, J. M.: Evaluation of the atmospheric water vapor content in a regional climate model using ground-based GPS measurements, J. Geophys. Res., 118, 329-339, doi:10.1029/2012JD018053, 2013.

Rocken, C., Ware, R. H., Hove, T. V., Solheim, F., Alber, C., and Johnson, J.: Sensing atmospheric water vapor with the Global Positioning System, Geophys. Res. Lett., 20, 2631-2634, 1993.

Rocken, C., Hove, T. V., and Ware, R. H.: Near real-time GPS sensing of atmospheric water vapor, Geophys. Res. Lett., 24, 32213224, 1997.

Rodgers, C. D.: Retrieval of atmospheric temperature and composition from remote measurements of thermal radiation, Rev. Geophys., 14, 609-624, 1976.
Rodgers, C. D.: Inverse Methods for Atmospheric Sounding - Theory and Practise, Vol. 2, World Scientific, Series on Atmospheric, Oceanic and Planetary Physics, 2000.

Saastamoinen, J.: Atmospheric correction for the troposphere and stratosphere in radio ranging of satellites, in: Geophys. Monogr. Ser. 15, edited by: Henriksen, S. W., 247-251, 1972.

Schneider, M., Hase, F., and Blumenstock, T.: Water vapour profiles by ground-based FTIR spectroscopy: study for an optimised retrieval and its validation, Atmos. Chem. Phys., 6, 811-830, doi:10.5194/acp-6-811-2006, 2006.

Schneider, M., Romero, P. M., Hase, F., Blumenstock, T., Cuevas, E., and Ramos, R.: Continuous quality assessment of atmospheric water vapour measurement techniques: FTIR, Cimel, MFRSR, GPS, and Vaisala RS92, Atmos. Meas. Tech., 3, 323 338, doi:10.5194/amt-3-323-2010, 2010.

Schneider, M., Barthlott, S., Hase, F., González, Y., Yoshimura, K., García, O. E., Sepúlveda, E., Gomez-Pelaez, A., Gisi, M., Kohlhepp, R., Dohe, S., Blumenstock, T., Wiegele, A., Christner, E., Strong, K., Weaver, D., Palm, M., Deutscher, N. M., Warneke, T., Notholt, J., Lejeune, B., Demoulin, P., Jones, N., Griffith, D. W. T., Smale, D., and Robinson, J.: Ground-based remote sensing of tropospheric water vapour isotopologues within the project MUSICA, Atmos. Meas. Tech., 5, 3007-3027, doi:10.5194/amt-5-3007-2012, 2012.

Slazek, M.: Analysis of evapotranspiration in the catchment of the Nurzec River, Poland using MODIS data, Miscellan. Geogr.Region. Stud. Devel., 18, 44-51, doi:10.2478/mgrsd-2014-0008, 2014.

Stevens, B. and Bony, S.: Water in the atmosphere, Phys. Today, 66, p. 29, doi:10.1063/PT.3.2009, 2013.

Takele Kenea, S., Mengistu Tsidu, G., Blumenstock, T., Hase, F., von Clarmann, T., and Stiller, G. P.: Retrieval and satellite intercomparison of $\mathrm{O}_{3}$ measurements from ground-based FTIR Spectrometer at Equatorial Station: Addis Ababa, Ethiopia, Atmos. Meas. Tech., 6, 495-509, doi:10.5194/amt-6-495-2013, 2013.

Turner, D., Lesht, B. M., Clough, S., Liljegren, J., Revercomb, H., and Tobin, D.: Dry bias and variability in Vaisala RS80-H radiosondes: the ARM experience, J. Atmos. Ocean. Tech., 20, 117-132, 2003.

Van Baelen, J., Aubagnac, J.-P., and Dabas, A.: Comparison of nearreal time estimates of integrated water vapor derived with GPS, radiosondes, and microwave radiometer, J. Atmos. Ocean. Tech., 22, 201-210, 2005.

Vedel, H. and Huang, X.-Y.: Impact of ground based GPS data on numerical weather prediction, J. Meteorol. Soc. Jpn., 82, 459472, 2004.

Vedel, H., Huang, X.-Y., Haase, J., Ge, M., and Calais, E.: Impact of GPS zenith tropospheric delay data on precipitation forecasts in Mediterranean France and Spain, Geophys. Res. Lett., 31, L02102, doi:10.1029/2003GL017715, 2004.

Voemel, H., Selkirk, H., Miloshecich, L., Valverde-Canossa, J., Valdes, J., Kyro, E., Kivi, R., Stolz, W., Peng, G., and Diaz, A.: Radiation dry bias of the VaisalaRS92 humidity sensor, J. Atmos. Ocean. Tech., 24, 953-963, 2007.

Wang, J., Zhang, L., Dai, A., Hove, T. V., and Baelen, J. V.: A near-global, 2 hourly data set of atmospheric precipitable water from ground-based GPS measurements, J. Geophys. Res., 112, D11107, doi:10.1029/2006JD007529, 2007. 
Wang, J., Zhang, L., Dai, A., Immer, F., Sommer, M., and Vomel, H.: Radiation Dry Bias Correction of Vaisala RS92 Humidity Data and Its Impacts on Historical Radiosonde Data, J. Atmos. Oceanic Technol., 30, 197-214, doi:10.1175/JTECH-D-1200113.1, 2013.

Wang, S., Fu, B. J., Gao, G. Y., Yao, X. L., and Zhou, J.: Soil moisture and evapotranspiration of different land cover types in the Loess Plateau, China, Hydrol. Earth Syst. Sci., 16, 2883-2892, doi:10.5194/hess-16-2883-2012, 2012.

Wang, Y., Liu, Y., Liu, L., Guo, Z., Ge, X., and Xu, H.: Retrieval of the change of precipitable water vapor with zenith tropospheric delay in the Chinese mainland, Adv. Space Res., 43, 82-88, 2009.
Yang, X. H., Sass, B. H., Elgered, G., Johansson, J. M., and Emardson, T. R.: A comparison of precipitable water vapor estimates by an NWP simulation and GPS observations, J. Appl. Meteorol., 38, 941-956, 1999.

Zeleke, T., Giorgi, F., Tsidu, G. M., and Diro, G. T.: Spatial and temporal variability of summer rainfall over Ethiopia from observations and a regional climate model experiment, Theor. Appl. Climatol., 111, 665-681, doi:10.1007/s00704-012-0700-4, 2013. 